\title{
Multi-layer perceptron-Markov chain-based artificial neural network for modelling future land-specific carbon emission pattern and its influences on surface temperature
}

\author{
Md.Abdul Fattah ${ }^{1}$ (D) . Syed Riad Morshed ${ }^{1}$ (D) $\cdot$ Syed Yad Morshed ${ }^{2}$
}

Received: 28 September 2020 / Accepted: 9 February 2021 / Published online: 23 February 2021

(c) The Author(s) 2021 OPEN

\begin{abstract}
Reliable and accurate environmental state prediction can help in long-term sustainable planning and management. Enormous land-use/ land-cover (LULC) transformation has been increasing the carbon emissions (CEs) and land surface temperature (LST) around the world. The study aimed to (i) examine the influences of land specific CEs on LST dynamics and (ii) simulate future potential LULC, CEs and LST pattern of Khulna City Corporation. Landsat satellite images of the year 2000, 2010 and 2020 were used to derive LULC, LST and CEs pattern and change. The correlation between land-use indices (NDBI, NDVI, NDWI) and LST was examined to explore the impacts of LULC change on LST. Unplanned urbanization has increased $11.79 \mathrm{Km}^{2}(26.10 \%)$ buildup areas and 25,268 tons of CEs during 2000-2020. The calculated $\mathrm{R}^{2}$ value indicates the strong positive correlation between CEs and LST. To simulate the future LULC, CEs and LST pattern for the year 2030 and 2040, multi-layer perceptron-Markov chain (MLP-MC)-based artificial neural network model was utilized with the accuracy rate of $94.12 \%, 99 \%$ and $98.48 \%$ for LULC, LST and CEs model, respectively. The simulation shows that by 2040 , buildup area will increase to $87.33 \%$, net CEs will increase by $19.82 \times 10^{4}$ tons, and carbon absorptions will decrease by $23.55 \times 10^{4}$ tons and $69.54 \%$ of the total study area's LST will be above $39^{0} \mathrm{C}$. Such predictions signify the necessity of implementing a sustainable urban development plan immediately for the sustainable, habitable and sound urban environment.
\end{abstract}

Keywords MLP-MC model · Carbon emission prediction · Land surface temperature · Land specific carbon emissions

\section{Introduction}

Environmental change is currently one of the main causes of concern around the world [1]. With the expansion of population and spontaneous extension of cities, land use patterns and biological systems have changed, prompting the arrangement of metropolitan situated natural difficulties around the globe [2]. Land use and land cover (LULC) type has been transforming enormously because of the many main impetuses. Thus, greenhouse gas (GHG) emissions, carbon emissions, climate change, environmental change, ecological change, and the random condition have been expanding which are making the climate of any region inadmissible for human home [3-5]. This is directly and indirectly accelerating global temperature. Currently, spatial GHG concentrations have risen from a $\mathrm{CO}_{2}$ equivalent of 280 to 450 ppm since the Industrial Revolution, but the proposed limit is 350 ppm [3]. This massive carbon

Supplementary Information The online version contains supplementary information available at https://doi.org/10.1007/s42452-02104351-8.

Md.Abdul Fattah, mafattah.kuet@gmail.com; Syed Riad Morshed, riad.kuet.urp16@gmail.com; Syed Yad Morshed, yadmorshed@ gmail.com | ${ }^{1}$ Department of Urban and Regional Planning, Khulna University of Engineering and Technology, Khulna, Bangladesh. ${ }^{2}$ Department of Civil Engineering, Khulna University of Engineering and Technology, Khulna, Bangladesh. 
emission and GHG emission have increased the earth's surface temperature with a rate of $0.2^{\circ} \mathrm{C}$ per decade in the last 30 years [4] while the average temperature increasing rate $0.0186^{\circ} \mathrm{C} /$ year has been observed in Bangladesh [5]. IPCC has projected a temperature rise of $1.1-6.4^{\circ} \mathrm{C}$ by the end of the twenty-first century and of $1^{\circ} \mathrm{C}$ to $1.5^{\circ} \mathrm{C}$ by 2050 in Bangladesh [6]. Global warming, surface temperature rise, climate change, ecological imbalance, ice melting and the rise of sea level, etc., have been increasing the significance of research on carbon emissions around the world so that in Bangladesh. Moreover, the increase in carbon emissions (CEs) has detrimental effects on living health and sustainable development.

LULC is considered the most perilous element of the environment which not only affects ecosystems and the environment but also climate and living beings. Human activities such as urbanization and construction activities may have economic benefits but influencing LULC change and affecting sustainability [7], increasing Land Surface Temperature (LST) [8] and also accelerating CEs [9]. The impact of massive CEs could be largely irreversible in the environment for 1000 years after CEs stops. Due to population growth, modernization and for better jobs, living and lifestyle people are moving towards the city and as a result urban area is expanding. Researchers have shown that LULC transformation is one of the main reasons for increasing CEs and the increase in carbon density in the atmosphere. The calculated net CEs due to LULC change are $12.5 \%$ of the total anthropogenic carbon emissions during 1990 to 2010 and $33 \%$ of total emissions over the last 150 years [10]. The net CEs from LULC dynamics has been calculated mostly in the carbon budget, which was accounted 1.4 (range: $0.4-2.3$ ) PgC/yr, 1.6 (0.5-2.7) PgC/ $\mathrm{yr}$ and $1.1 \pm 0.7 \mathrm{PgC} / \mathrm{yr}$ in the year 1980s, 1990s and from 2000 to 2009 , respectively $[13,14]$. IPCC reported the highest increase in global average temperatures in the last century because of the increase in anthropogenic concentrations of GHG that contributing to the warming of Earth's surface [1].

Topic related to LULC change such as simulation of future potential LULC patterns and their consequences on the environment and ecosystem has recently attracted interest from a wide range of literature [15-19]. In previous studies, researchers have explained the impact of LULC [5, $20,21]$ CEs $[1,9,22-24]$. No previous study has discussed land use-based CEs, their consequences and effects on the environment in the context of Bangladesh. Moreover, the impact of spatiotemporal CEs on LST dynamics and their relationship is not discussed in any studies. Researchers have illustrated the impact of LULC change in different urban and rural areas on LST in many previous studies [25-31]. Similar studies have been done in some cities in Bangladesh including Dhaka [32-34], Chattogram [11,
35], Rajshahi [36] and Cumilla [7]. Few researchers have highlighted the LULC change in Khulna city [37-39] but the spatiotemporal change of LST pattern and impact of LULC on LST of the growing city Khulna is not illustrated.

Many scholars simulated the future LULC scenarios for different study areas. To simulate the future LULC transformation, several models, such as Markov chain, Cellular Automata [17], CLUE [19], Agent-based model [18], Multi-Layer Perceptron-Markov Chain (MLP-MC) [36], have been developed. Subedi et al. [40] and Arsanjani et al. [41] explained MLP-MC model as the most effective model for simulating future spatiotemporal changes with highprecision LULC transformation. Limited simulation studies have been found based on LULC and LST but yet no study has been conducted by modeling future CEs pattern. So far yet, no study has been carried out on Khulna City to predict the future LULC, CEs pattern and their impacts on surface temperature.

This study used artificial neural network (ANN)-based MLP-MC model to simulate the future potential LULC, CEs and LST pattern of Khulna city accurately. The present study filled all the gaps and visualized the LULC, CEs and LST change pattern, examined the impact of spatiotemporal LULC change on LST and influences of CEs pattern on LST change. The overall study signifies the importance of the implementation of proper planning regulations and will be helpful to the engineers, policymakers, urban planners and city's responsible authorities to take necessary steps for mitigating the environmental issues in this growing city.

\section{Theory for how LST depends on Carbon emission}

Climate model projections show a basic emerging relationship for our future climate: surface warming rises almost linearly with cumulative $\mathrm{CO}_{2}$ emissions since pre-industrial times [42]. How surface warming increases with cumulative $\mathrm{CO}_{2}$ emissions is illustrated in equation $[4,43]$. The global temperature response to increased atmospheric CE is quantified by measurements such as transient climate response and climate sensitivity equilibrium. The relationship between carbon emission and climate temperature was established by Matthews et al. [43] which is shown in Eq. 1.

$\mathrm{CTR}=\frac{\Delta \mathrm{T}}{\mathrm{ET}}=(\Delta \mathrm{T} / \Delta \mathrm{CA}) \times(\Delta \mathrm{CA} / \mathrm{ET})$

Where $C T R=$ Carbon-temperature response.

$\Delta \mathrm{T} / \Delta \mathrm{C}_{\mathrm{A}}=$ Temperature change per unit atmospheric carbon increase. 
$\Delta C_{A} / E_{T}=$ Airborne fraction of cumulative carbon emissions.

The sensitivity of surface warming depends on carbon and radiative forcing. When the radioactive forcing is affected only by the CE change in the atmosphere, the mean surface temperature $\Delta \mathrm{T}$ is measured by Eq. 2 . If other non- $\mathrm{CO}_{2}$ radiative contributions also affect the radiative forcing, the mean surface temperature $\Delta \mathrm{T}$ is measured by Eq. 3 [42]. For more details about these terms, the readers are requested to follow $[42,44]$.

$\Delta \mathrm{T}=\Delta \mathrm{L} \times\left(\frac{\Delta \mathrm{T}}{\Delta \mathrm{R}}\right) \times\left(\frac{\Delta \mathrm{R}}{\Delta \mathrm{L}}\right)$

$\Delta T=\Delta L \times\left(\frac{\Delta T}{\Delta R}\right) \times\left(\frac{\Delta R}{\Delta R C O 2}\right) \times\left(\frac{\Delta R C O 2}{\Delta L}\right)$

Where $\Delta \mathrm{L}=$ Change in the total carbon emission.

$\Delta T / \Delta R=T$ The ratio of the surface warming and the radiative forcing.

$\Delta \mathrm{R} / \Delta \mathrm{L}=$ Radiative forcing and net carbon emissions ratio.

$\Delta R / \Delta R_{\mathrm{CO}_{2}}=$ Ratio of radiative forcing and the radiative forcing from atmospheric $\mathrm{CO}_{2}$.

$\Delta \mathrm{R}_{\mathrm{CO} 2} / \Delta \mathrm{L}=$ Ratio of the radiative forcing from atmospheric $\mathrm{CO}_{2}$ and change in total carbon emission.

With rising atmospheric $\mathrm{CO}_{2}$ the radiative heat flux at the sea surface increases logarithmically. IPCC established Eq. 4 in 1990 for measuring the surface temperature $(\Delta T$ surface) for $\mathrm{CE}$ [45]. Considering $\mathrm{CO}_{20}$ as the unperturbed concentration of $\mathrm{CO}_{2}$,

$\Delta$ Tsurface $=\Delta \mathrm{T}$ surface $2 \times \mathrm{CO} 2 \frac{\ln (\mathrm{CO} 2 / \mathrm{CO} 2 \mathrm{o})}{\ln 2}$

where $\Delta T$ surface $2 \times \mathrm{CO}_{2}$ is the surface temperature rise for atmospheric $\mathrm{CO}_{2}$ doubling and ranges from 2 to $4.5 \mathrm{~K}$, with an average of $3 \mathrm{~K}$, from a variety of climate models [45]. The details of the relationship between surface temperature and CE are described in the literature $[42,43,45]$.

\section{Study area}

Khulna, the $3^{\text {rd }}$ largest divisional headquarters and one of the four major cities in Bangladesh are situated in the south-west corner of the country [46]. Sundarbans, the largest mangrove forest $(140,000 \mathrm{ha})$ and one of the UNESCO World Heritage Sites in the world, is located in this division. Due to this, the division is environmentally sound and the city is considered as a green city [47].
The urban population and the amount of urban area of Khulna City Corporation (KCC) have been increasing at a high rate for the last few decades $[39,47]$. This has been upsetting the environmental and ecological balance in the KCC area [48]. KCC area is $45.154 \mathrm{~km}^{2}$, is located in between $24^{\circ} 45^{\prime}$ and $24^{\circ} 54^{\prime}$ north latitudes and in between $89^{\circ} 28^{\prime}$ and $89^{\circ} 35^{\prime}$ east longitudes [61]. About 1.56 million people live in KCC [46]. The city is bounded by the Bhairab river on the north side, the Rupsa River on the middle and the Pasur river on the south side which flows along the east side of the city, the Mayur on the north side and the Hatia River on the south side which flows along the west side of the city (Fig. 1).

The average temperature of Khulna is $26.37^{\circ} \mathrm{C}$ and is increasing by a rate of $0.005^{\circ} \mathrm{C} /$ year. The annual total rainfall is $1630 \mathrm{~mm}$ [49]. Figure 2 shows the increasing trend of maximum and minimum average temperature in Khulna city. In the last 20 years, the highest temperature was observed $40.7{ }^{\circ} \mathrm{C}$ in April, 2016 and the average minimum atmospheric temperature was observed $22.13{ }^{\circ} \mathrm{C}$, whereas it was $21.87^{\circ} \mathrm{C}$ in the last 69 years. Both annual total rainfall and monthly total rainfall have increased in Khulna. After 2000, the annual average total rainfall measured $1875.134 \mathrm{~mm}$.

\section{Methods and materials}

\subsection{Dataset preparation}

Three Multi-spectral Landsat satellite images were collected from the United States Geological Survey (USGS) for the year 2000, 2010 and 2020 to extract the LULC, CEs and the LST data. The Landsat program consists of a series of satellite missions under joint supervision by NASA and USGS. Landsat satellites have the best land resolution and spectral bands to monitor land use effectively and to record LULC changes as a result of urbanization, climate change, drought, bio-mash changes, wildfire and many other natural or human changes [33, 34, 36]. These three satellite images were taken in the same month (April) to avoid the seasonal effects during data analysis. Due to less possibility of rainfall in Khulna during April, the accuracy or acceptability of the LST result is higher than in other months. The maximum cloud coverage was set to less than $10 \%$ during collecting the images. The Landsat satellite images were of $30 \mathrm{~m}$ resolution and dated 17/04/2000, 11/04/2010 and 06/04/2020 have been collected. For slope and elevation, the data were collected from google earth and imported into the GIS environment and utilized in the MLP-MC model. 


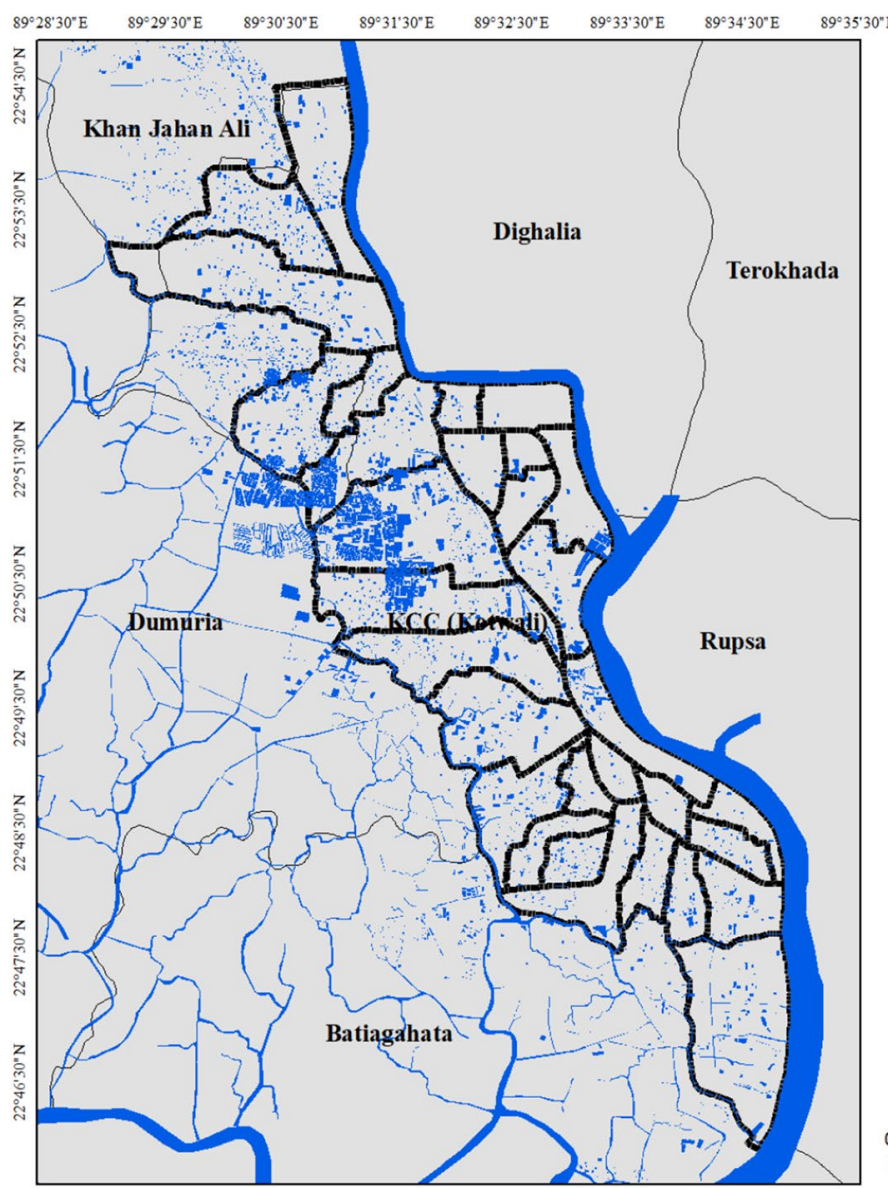

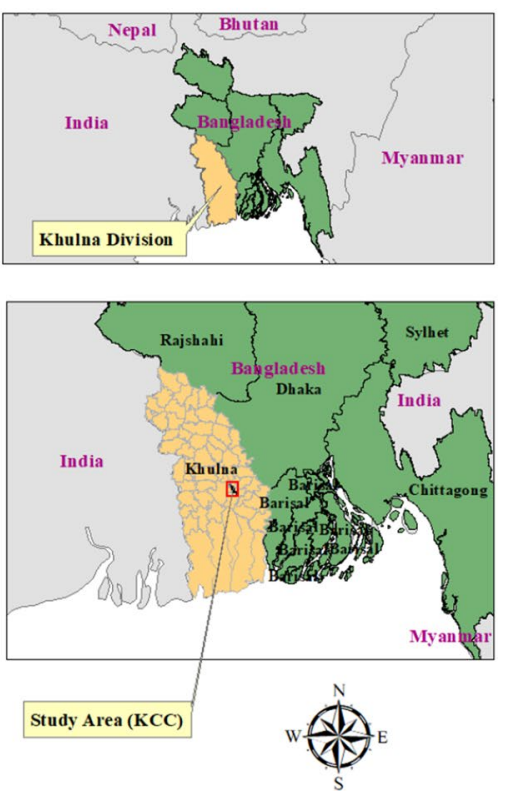

Legend

$\checkmark 3$ Bangladesh Country Boundary

3 Khulna Division Boundary

3 Khulna Thana Boundary

3. Khulan City Corporation Ward Boundary KCC Waterbody

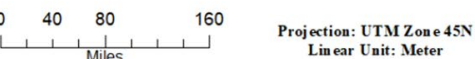

Fig. 1 Location map visualizing the study area

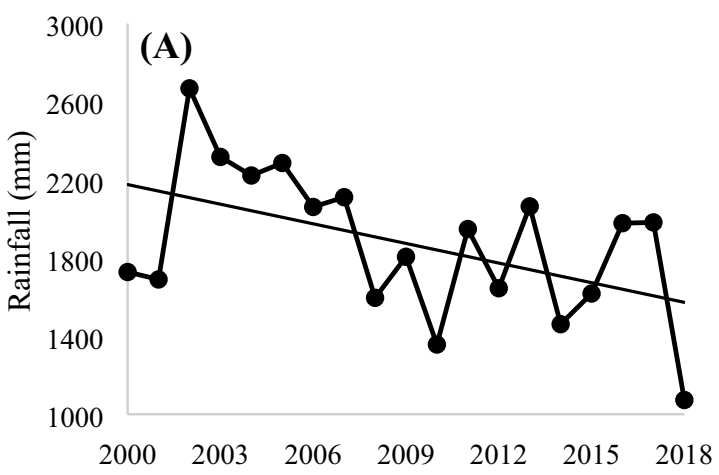

32.5

(B)

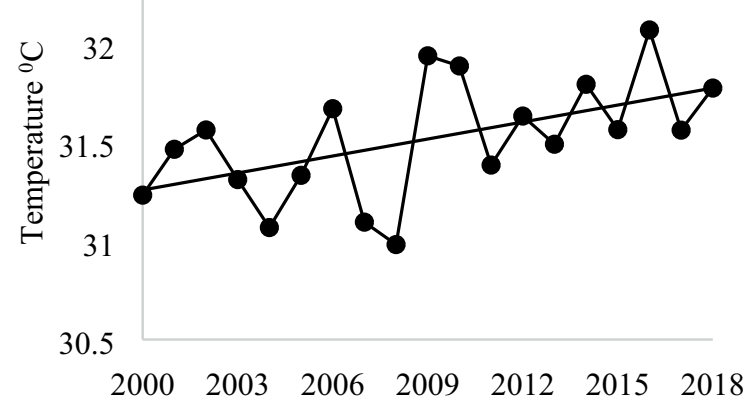

Fig. 2 Atmospheric trend scenario in Khulna City $\mathbf{a}$ annual total rainfall $\mathbf{b}$ average annual temperature

\subsection{Land use classification and land cover mapping}

For a better quality of the images, the radiometric and atmospheric correction has been conducted and enhanced by applying majority filter techniques in ERDAS Imagine 2014 version. The generation of composite band combinations such as natural color composite, true-color composite, false-color composite is done to classify the LULC type in the study area [36]. Blue, green, red and nearinfrared bands were used for Landsat 5 TM images and Landsat $8 \mathrm{OLI}$ images to find true color during data processing in ERDAS Imagine 2014 and ArcGIS 10.6 version. The land cover type has been classified into five categories (Table 1) based on the proper understanding of LULC 
Table 1 Used land cover classes description

\begin{tabular}{ll}
\hline Land cover types & Description \\
\hline BU & $\begin{array}{c}\text { Industrial, residential, commercial, road net- } \\
\text { work and any kinds of infrastructures }\end{array}$ \\
VG & Trees and forest areas \\
AL & Grassland, cropland \\
VL & Playground, bare soils, open space, landfill sites \\
WB & Ponds, canals, lake, river and wetlands
\end{tabular}

dynamics and applied maximum likelihood supervised classification method $[50,51]$ to identify the land cover pattern in the study area for the selected year. Bands were used 4-3-2 (Color Infrared) and 3-2-1 (True Color) for Landsat 5 images, 4-3-2 (True Color) and 5-4-3 (Color Infrared) for Landsat 8 images. Then the land cover type change direction during the study period 2000 to 2020 has been analyzed in ArcMap 10.6 version. To check the accuracy of the classification, more acceptable and best quantitative image classification accuracy measurement techniques named Kappa statistics and confusing matrix were calculated [52, 53]. Using Eqs. 5-8, Kappa coefficient, user accuracy, producer accuracy and overall accuracy of each LULC were calculated. Around 150 training sites have been randomly chosen for each image to ensure that each LULC type is covered by all spectral groups. Stratified random sampling method has capability to reduce biasness of accuracy assessment by taking equal number of sample point from each feature classes.

$\mathrm{BU}=$ Build up area, $\mathrm{VG}=$ Vegetation land, $\mathrm{VL}=$ Vacant land, $\mathrm{AL}=$ Agricultural land, $\mathrm{WB}=$ Waterbody.
Table 2 Carbon emission coefficient $(\delta i)$ for different land cover types

\begin{tabular}{lll}
\hline LULC Types & $\begin{array}{l}\text { Carbon Emission Coefficient } \\
\left(\mathrm{kg}(\mathrm{C}) . \mathrm{m}-2 . \mathrm{a}-{ }^{1}\right)\end{array}$ & Used in this study \\
\hline BU & +0.0742 & +0.0742 \\
WB & $-0.0509,-0.0410,-0.0459$ & -0.0459 \\
AL & +0.0497 & +0.0497 \\
VL & $-0.021,-0.0527$ & -0.0527 \\
VG & $-0.0645,-0.0527$ & -0.0645 \\
\hline
\end{tabular}

to 2020. Equation 9 was used to estimate carbon emissions from each LULC type [11]. The agricultural land and buildup areas are the source LULC types of CEs and the vegetation, vacant land and waterbodies are the carbon sinks or absorptive LULC types.

$E i=\sum e i=\sum S i \times \delta i \times\left(\frac{M C O 2}{M C}\right)$

Here

$$
\begin{aligned}
& \mathrm{Ei}=\text { Carbon emissions from land use. } \\
& \mathrm{i}=\text { land-use type. } \\
& \mathrm{Si}=\text { Area of land } \mathrm{i} \text {. } \\
& \delta \mathrm{i}=\text { Carbon emission coefficient for land } \mathrm{i}, \\
& \mathrm{M}_{\mathrm{CO} 2} / \mathrm{M}_{\mathrm{C}}=44 / 12=3.6667 \text {. }
\end{aligned}
$$

$\delta i$ 's positive values indicate carbon emissions while negative values indicate carbon absorption [11]. Different LULC types were identified in this study through a supervised image classification method while the value of the

Kappacoefficient $=\frac{\text { Totalsamplenumber } \times \text { Totalcorrectedsamplenumber }-\sum(\text { col.tot } \times \text { rowtot })}{\text { Totalsamplenumber }{ }^{2}-\sum \text { col.tot } \times \text { rowtot }} \times 100 \%$

Useraccuracy $=\frac{\text { Num. of correctly classified pixels in each category }}{\text { Total numb of reference pixels in each category (row total) }} \times 100 \%$

Produceraccuracy $=\frac{\text { Numofcorrectlyclassifiedpixels(diagonal) }}{\text { Totalnumbofreferencepixelsineachcategory(column) }} \times 100 \%$

Overallaccuracy $=\frac{\text { Total num of corrected classified pixels (diagonal) }}{\text { Total num of reference pixels }} \times 100 \%$

\subsection{Carbon emission estimation}

The research focused on estimating land-specific carbon emissions, and emission change during the year 2000 carbon emission coefficient for each LULC type has been proposed in previous studies. The carbon emission coefficient for different land cover types in Table 2 has been collected from previous studies $[4,54,55]$. Though there are 
different emission factors for estimating CEs from different LULC types. This study used coefficients which are mostly used in recent studies and are reliable for this study to get an accurate result [54-57]. Net carbon emissions were also calculated by subtracting absorptions from emissions.

\subsection{Derivation of LST}

The land surface temperature has been estimated for the year $2000-2020$ by using Landsat Thermal bands. Landsat
Here

$P_{\mathrm{v}}$ is the vegetation proportion calculated following Eq. (14)

$P y=\left[\frac{N D V I-N D V I m i n}{N D V I-N D V I m a x}\right]^{2}$

To obtain the LST values in Celsius $\left({ }^{\circ} \mathrm{C}\right), 273.15$ was extracted from the initial values $(\mathrm{K})$.

In Landsat 5 images, band 6 is the thermal band which is used for the derivation of LST. Following steps were followed to calculate the LST from Landsat 5 images $[36,58]$.

$L \lambda=((L M A X \lambda-L M I N \lambda) /(Q C A L M A X-Q C A L M I N)) \times(Q C A L-Q C A L M I N)+L M I N \lambda$

images contain digital numbers. The following steps were followed to estimate the LST [58].

$L_{\lambda}=A_{\lambda}+M_{L}^{*} Q_{C A L}$

Here

$\mathrm{L}_{\lambda}=$ TOA Spectral Radiance $\left(\mathrm{W} /\left(\mathrm{m}^{2} \times \mathrm{sr} \times \mu \mathrm{m}\right)\right)$.

$M_{L}=$ Radiance multiplicative scaling factor for the band.

$A_{L}=$ Radiance additive scaling factor for the band.

$\mathrm{Q}_{\mathrm{CAL}}=\mathrm{Quantized}$ calibrated pixel value in Digital Numbers (DN).

In the second step the TOA spectral radiance $\left(L_{\lambda}\right)$ values are converted into At-Satellite Brightness Temperature (TB)

$\mathrm{TB}=\frac{\mathrm{k}_{2}}{\ln \frac{\mathrm{k}_{1}}{\mathrm{~L}_{1}+1}}$

Here

$\mathrm{TB}=$ At-Satellite Brightness Temperature, Kelvin (K).

$\mathrm{K}_{1}, \mathrm{~K}_{2}=$ Thermal conversion constants for the band.

The TOA Brightness Temperature converted to LST (In Kelvin) using the formula 12.

$L S T=[T B /(1+(\lambda * T B / \alpha)) * \ln \varepsilon]$

Here

$$
\begin{aligned}
& \lambda=\text { the wavelength of emitted radiance. } \\
& \mathrm{a}=\mathrm{hc} / \mathrm{k}\left(1.438 \times 10^{-2} \mathrm{mK}\right) . \\
& \mathrm{h}=\text { Planck constant }\left(6.626 \times 10^{-34} \mathrm{~J} \mathrm{~s}-1\right), \mathrm{c}=\text { velocity of } \\
& \text { light }\left(2.998 \times 10^{8} \mathrm{~m} \mathrm{~s}^{-1}\right) . \\
& \mathrm{k}=\text { Boltzmann constant }\left(1.38 \times 10^{-23} \mathrm{~J} \mathrm{~K}^{-1}\right) . \\
& \varepsilon=\text { surface emissivity } \\
& \varepsilon=0.004 * P v+0.986
\end{aligned}
$$

where

$L_{\lambda}$-TOA Spectral Radiance $\left(W /\left(m^{2} \times s r \times \mu m\right)\right)$.

$\mathrm{L}_{\text {MAX }}=$ The spectral radiance that is scaled to QCALMAX $\left(\mathrm{W} /\left(\mathrm{m}^{2} \times \mathrm{sr} \times \mu \mathrm{m}\right)\right)$.

$\mathrm{L}_{\text {MINX }}=$ The spectral radiance that is scaled to QCALMIN $\left(W /\left(m^{2} \times s r \times \mu m\right)\right)$.

$\mathrm{QCAL}=$ The quantized calibrated pixel value in Digital Numbers.

$\mathrm{QCAL}_{\text {MAX }}=$ The maximum quantized calibrated pixel value.

$\mathrm{QCAL}_{\text {MIN }}=$ The minimum quantized calibrated pixel value.

\subsection{Land use indices analysis}

To identify the influence of different LULC changes on LST, three land-use indices namely Normalized Difference Vegetation Index (NDVI), Normalized Difference Water Index (NDWI) and Normalized Difference Buildup Index (NDBI) are used. These all indices were mostly used in many previous researches. The readers are referred to Guha et al. [59] for the detailed methodology of NDBI, for NDVI and NDWI indices Grigoraș \& Urițescu 2019; Kafy et al. 2020 [36, 58] for NDWI index. The author used these indices for regression analysis with LST to identify the impact of different LULC types on LST.

\subsection{Simulations of future scenario}

To predict the future LULC scenario, Land Change Modeler (LCM) of TerrSet Geospatial Monitoring and Modeling Software and QGIS was used in MLP-MC neural network method. Because of its training guidelines, it is also called a "back-propagation" network. The LCM tool is used to evaluate losses and gains, detect categories, net shifts [36]. The MLP-MC model contains both static 
Table 3 Different parameters used in this study to simulate future LULC scenario

\begin{tabular}{lccc}
\hline Model parameter & Influence order & \\
\cline { 2 - 4 } & 2010 to 2020 & 2020 to 2030 & 2030 to 2040 \\
\hline Slope & 9 & 9 & 6 \\
Distance to road & 8 & 10 & 7 \\
All LULC to urban trend & 4 & 11 & 8 \\
Agriculture to urban trend & 2 & 1 & 9 \\
Vacant to urban trend & 1 & 8 & 10 \\
Vegetation to urban trend & 11 & 7 & 11 \\
Waterbody to urban trend & 13 & 6 & 12 \\
Agriculture to all LULC trend & 12 & 12 & 4 \\
Other to urban trend & 3 & 5 & 3 \\
Vegetation to all LULC trend & 10 & 4 & 2 \\
Waterbody to all LULC trend & 6 & 3 & 1 \\
Urban disturbance & 5 & 2 & \\
Digital elevation model (DEM) & 7 &
\end{tabular}

and dynamic aspects of high-precision LULC transformation and is commonly used by many previous studies for LULC prediction [60,61]. Several factors influence the change of land cover types. In this study, 13 factors (Table 3) were considered. For the prediction of the LULC scenario, the LULC maps of the year 2000 and 2010 were used as independent variables in QGIS. The simulated data for 2020 and classified LULC data for 2020 were compared. The model provided the best outcomes in the study area for which, MLP-MC simulation for 2030 and 2040 was carried out and also determined the possible changes.

The urban disturbance and the distance of locations from the road were calculated from the GIS data, collected from the KCC authority. The data used in the other factors in this study were derived from landuse classification. These factors in Table 3 influence to change LULC pattern [36, 62]. The CA-MC transition matrix data were utilized as influential factors (trend of one LULC type to another LULC type) for simulating LULC change. The LULC transition matrix for the year 2000 to 2020, the LULC were simulated for every 10 consecutive years. The readers are referred to follow the literature [36, 60-62] for the details of the MLP-MC-based ANN process and influencing factors in Table 3. To check the accuracy of the simulated model, percentage error, accuracy assessment and RMSE were calculated. For model validation, a statistical similarity was performed by comparing the predicted and observed results of LULC of the year 2020. Using this MLP-MC model, the carbon emissions and LST also simulated for the year 2030 and 2040. The higher value of accuracy and lower value of percentage error, the RMSE value indicates the best-fitted prediction model $[10,19]$. Figure 3 represents the methodological flow that was followed to fulfill the aim of this study.
Fig. 3 Methodological conceptual framework

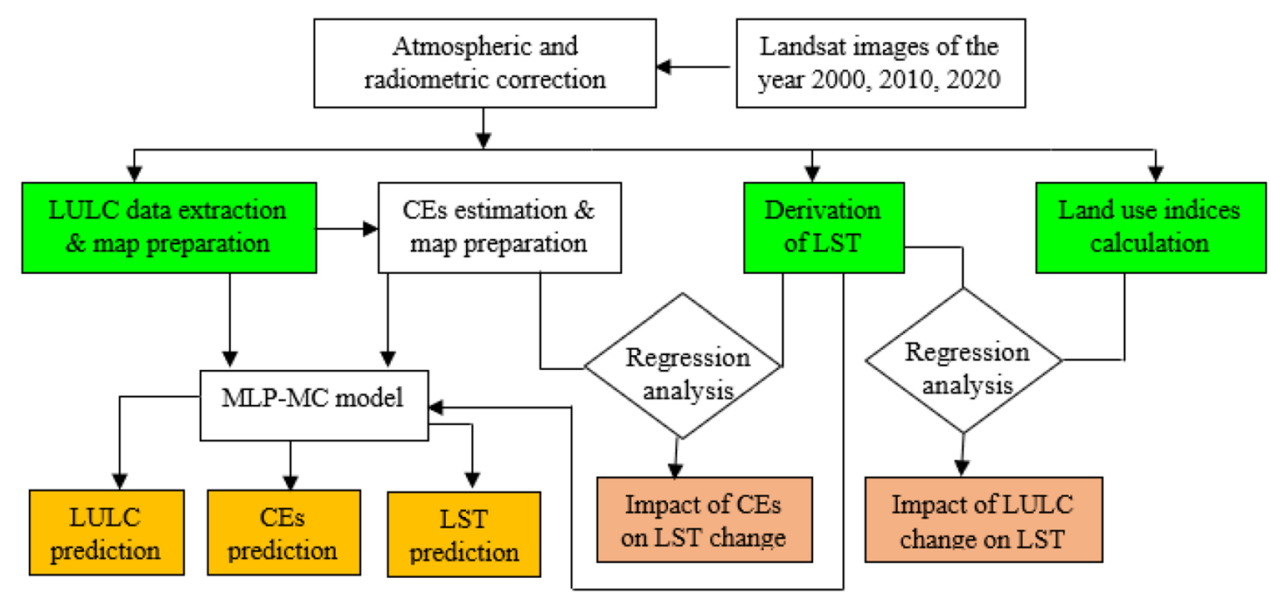


Table 4 Calculated accuracy assessment value

\begin{tabular}{|c|c|c|c|c|c|c|}
\hline \multirow[t]{2}{*}{ LULC Accuracy } & \multicolumn{2}{|l|}{2000} & \multicolumn{2}{|l|}{2010} & \multicolumn{2}{|l|}{2020} \\
\hline & Producer's (\%) & Users (\%) & Producer's (\%) & Users (\%) & Producer's (\%) & Users (\%) \\
\hline BU & 88.89 & 100 & 83.33 & 100 & 100 & 87.50 \\
\hline $\mathrm{AL}$ & 100 & 100 & 100 & 100 & 100 & 100 \\
\hline VG & 88.89 & 100 & 100 & 100 & 100 & 100 \\
\hline VL & 100 & 80 & 87.50 & 87.50 & 83.33 & 100 \\
\hline WB & 100 & 80 & 100 & 80 & 100 & 100 \\
\hline Overall accuracy & $93.33 \%$ & & $93.33 \%$ & & $96.67 \%$ & \\
\hline Kappa Statistics & 0.9143 & & 0.915 & & 0.9577 & \\
\hline
\end{tabular}

\section{Analysis and interpretation}

\subsection{Accuracy assessment}

The accuracy assessment was carried out by calculating the overall accuracy, producer's accuracy, user's accuracy and Kappa Statistic value using Eqs. 5-8 (Table 4). The value of the overall accuracy is $93.33 \%, 93.33 \%$ and $96.67 \%$ for the year 2000, 2010 and 2020, respectively, and the Kappa coefficient values are $0.9143,0.915$ and 0.9577 which indicates the good accuracy of the classified data and suitable for urban expansion detection. Also, the results meet the recommended Kappa Statistics values recommended in the literature $[53,63]$.

\subsection{LULC change analysis}

\subsubsection{Land cover mapping}

Using the supervised image classification method, the LULC data were extracted (Table 5) and prepared map for the year 2000, 2010 and 2020 (Fig. 4). Table 5 shows that, in 2000 vegetation land covered almost $30.42 \%$ of the total area, then periodically agricultural land $11.46 \%$, waterbody $5.08 \%$ and vacant area $0.13 \%$. Though buildup areas were the maximum coverage of LULC type $(52.19 \%)$ in 2000, unplanned urban expansion and massive construction lead to an increased buildup area to $67.97 \%$ in 2010 and $79.01 \%$ in 2020 . Such an increase in the buildup area has put enormous pressure on other land cover types.
In 2020, agricultural land declined to $3.91 \%$, vacant land $0.04 \%$ and waterbodies $4.92 \%$ in the study area. This declination of environment-friendly LULC areas such as vegetation, waterbodies and agricultural land has resulted in several environmental problems at KCC and accelerated the carbon emissions and LST. Figure 4 shows that the southern part of the KCC has the highest concentration of buildup area and the lowest presence of other land cover types. As the growth center of the KCC is located in the southern corner and maximum industry and factories are located in this area, urban expansion mostly took place in this place. That's why the landscape in this portion has experienced the most LULC transformation in the last two decades. Several factors, such as massive urban growth, unplanned urban population growth, and rural-urban migration tendency led to such changes.

\subsubsection{LULC transformation direction analysis}

The LULC change direction and transition matrix were identified using the CA Markov Model in the GIS environment. LULC change direction analysis (Fig. 5,6 ) shows that vegetation area decreased by $18.3 \%$, waterbodies $0.2 \%$, vacant land $0.1 \%$ and agricultural land $7.55 \%$ during the year 2000 to 2020 and these contributed to the increase in buildup area by $26.1 \%$. Land-use change direction shows the increase in agricultural land from $11.46 \%$ to $14.94 \%$, vacant land from $0.13 \%$ to $1.37 \%$, buildup area $52.91 \%$ to $67.97 \%$ and declination of vegetation area from $30.42 \%$ to $11.95 \%$ and waterbody area from $5.08 \%$ to $3.77 \%$ of the total study area during 2000 to 2010 . In the next decades,
Table 5 Status of different LULC types during 2000-2020

\begin{tabular}{lllllllc}
\hline Year & Unit & $\mathrm{AL}$ & $\mathrm{BU}$ & $\mathrm{VL}$ & $\mathrm{VG}$ & WB & Total \\
\hline 2000 & Area $\left(\mathrm{Km}^{2}\right)$ & 5.17 & 23.88 & 0.06 & 13.73 & 2.29 & 45.14 \\
& Percentage & $11.46 \%$ & $52.91 \%$ & $0.13 \%$ & $30.42 \%$ & $5.08 \%$ & $100.00 \%$ \\
2010 & Area $\left(\mathrm{Km}^{2}\right)$ & 6.74 & 30.69 & 0.62 & 5.39 & 1.70 & 45.14 \\
& Percentage & $14.94 \%$ & $67.97 \%$ & $1.37 \%$ & $11.95 \%$ & $3.77 \%$ & $100.00 \%$ \\
2020 & Area $\left(\mathrm{Km}^{2}\right)$ & 1.77 & 35.67 & 0.02 & 5.47 & 2.22 & 45.14 \\
& Percentage & $3.91 \%$ & $79.01 \%$ & $0.04 \%$ & $12.11 \%$ & $4.92 \%$ & $100.00 \%$ \\
\hline
\end{tabular}



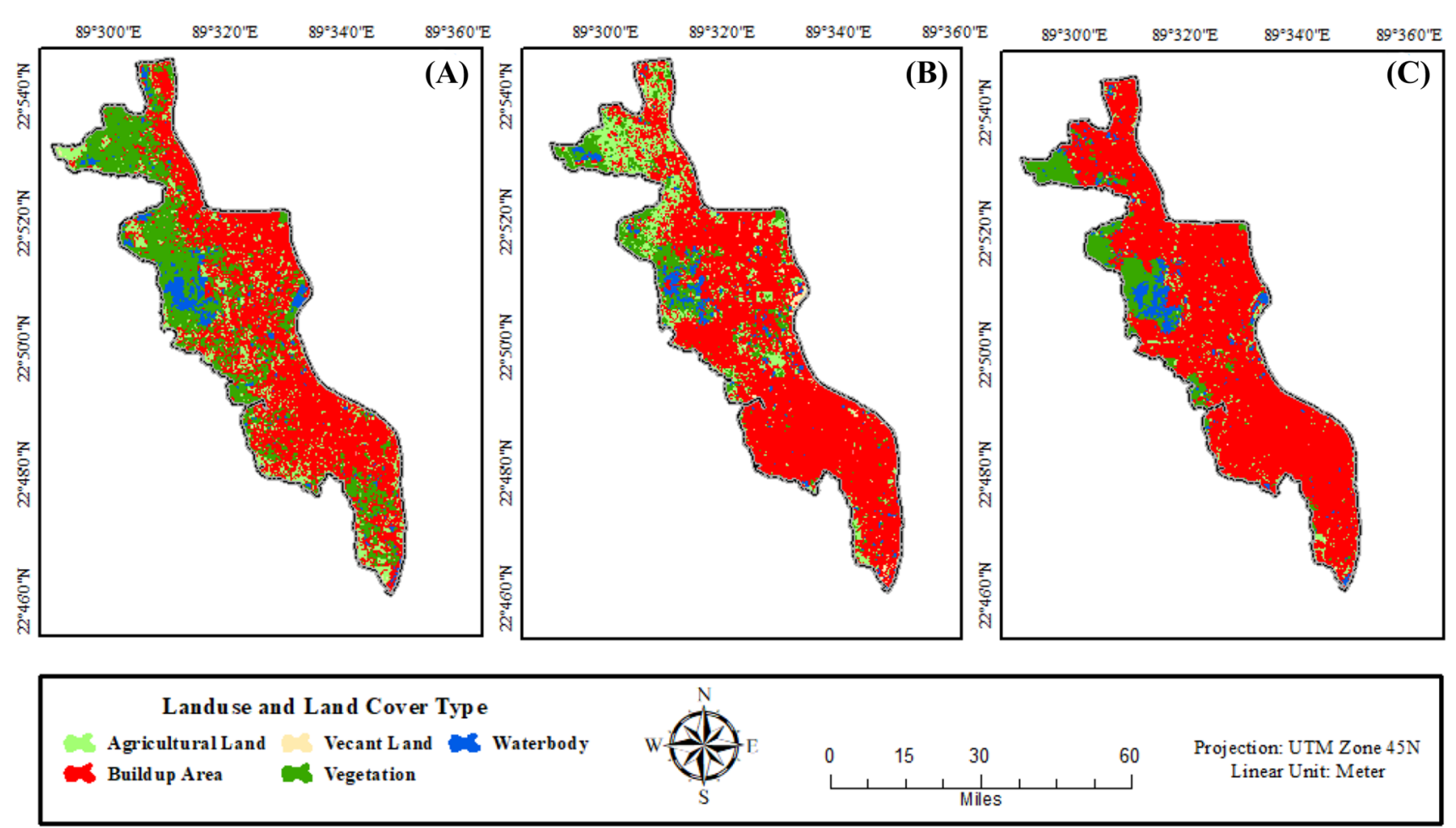

Fig. 4 LULC map of the KCC area for a 2000 b 2010 and c 2020

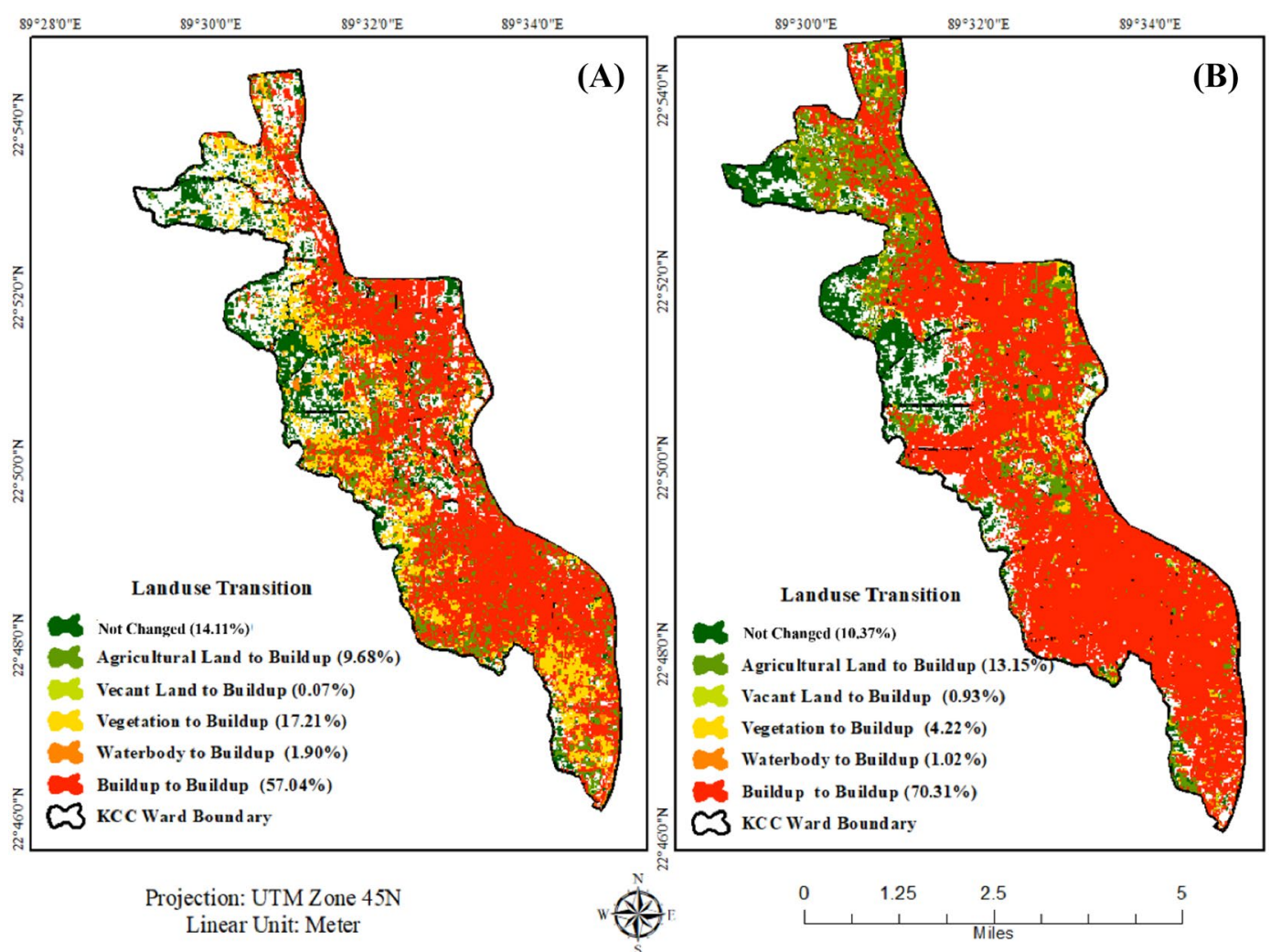

Fig. 5 Transition from all LULC to buildup area during a 2000-2010 and b 2010-2020 
the agricultural land cover decreased by 4.98 sq.km (11\%) and buildup area increased by $4.98 \mathrm{sq} . \mathrm{km}$ (11\%). Though agricultural and vacant land increased during 2000 to 2010 but decreased in the next decades by $11 \%$ and $1.33 \%$, respectively. Figure 5 shows that due to urban expansion during the study period, different LULC types have been transformed into buildup areas which were quantified by the CA Markov model and presented in Table 6. The LULC change matrix in Table 5 shows the significant increase in the buildup area from $23.88 \mathrm{Km}^{2}$ to $35.67 \mathrm{~km}^{2}(52.91 \%$ to $79.01 \%$ ), where agricultural land was $3.6796 \mathrm{~km}^{2}$, vegetation land $9.3197 \mathrm{~km}^{2}$. Only a few portions remained unaltered.

\subsection{Spatiotemporal carbon emissions estimations}

Using LULC statistics in Table 5, total CEs, carbon absorptions and net carbon emissions were estimated for the year 2000, 2010 and 2020 through utilizing Eq. 9 and presented in Table 7. Figure 7 represents the spatiotemporal carbon emissions and absorptions pattern in the study area. Negative figures refer to carbon sink or absorptions, while the positive figures refer to carbon emission sources (Table 7). The buildup area and vegetation area were the largest contributors to carbon emissions and absorptions, respectively (Table 7). Buildup areas found to contribute more than $85 \%$ of total CEs and vegetation area accounted for the absorptions of more than $75 \%$ of total carbon absorptions over the last two decades. In 2000, total CEs estimated 9430.6 tons from
Fig. 6 Land Cover change direction during 2000-2020

Table 6 Statistics of CA Markov LULC transition matrix

Table 7 Land-use specific carbon emissions, absorptions and net carbon emissions scenario of the KCC area for the year 2000, 2010 and 2020. (unit: tons/year)

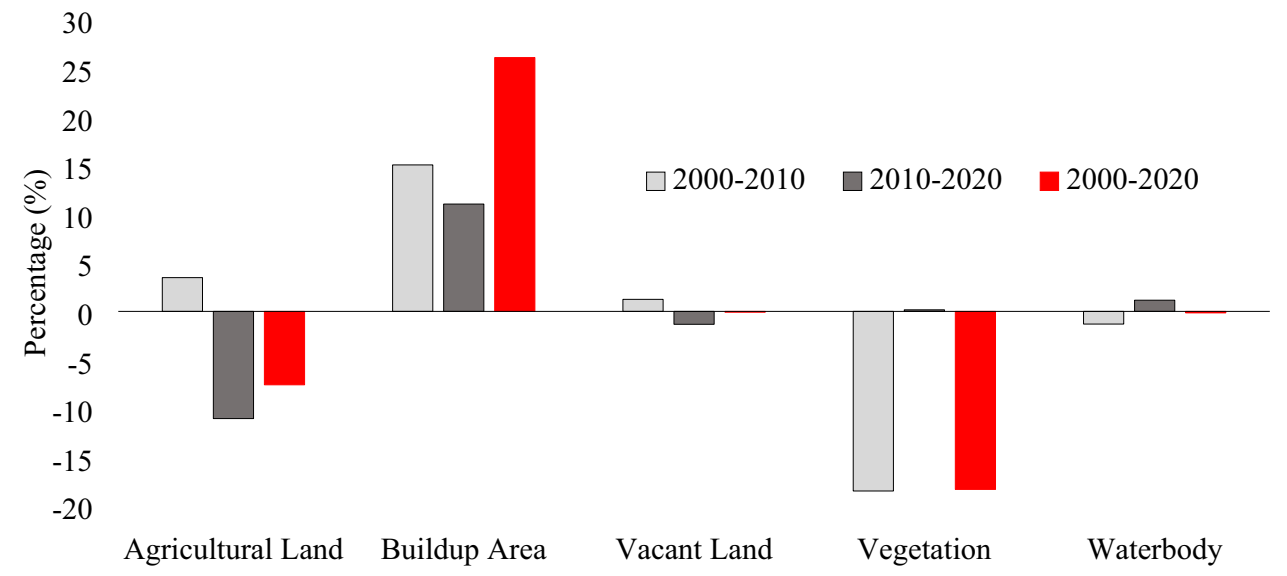

\begin{tabular}{llrlllr}
\hline LULC types & AL & BU & VL & VG & WB & \multicolumn{1}{c}{ Total } \\
\hline AL & 0.6723 & 3.6796 & 0.0086 & 0.7629 & 0.0361 & 5.1595 \\
BU & 0.7717 & 22.0836 & 0.0094 & 0.6467 & 0.2357 & 23.7472 \\
VL & 0.0084 & 0.1302 & 0.0100 & 0.0213 & 0.0200 & 0.1899 \\
VG & 0.2243 & 9.3197 & 0.0009 & 3.3317 & 0.9319 & 13.8085 \\
WB & 0.0732 & 0.5788 & 0.0009 & 0.5922 & 1.0039 & 2.2494 \\
Total & 1.7499 & 35.7920 & 0.0298 & 5.3548 & 2.2276 & 45.1440 \\
\hline
\end{tabular}

\begin{tabular}{|c|c|c|c|c|c|c|c|c|}
\hline \multirow[t]{2}{*}{ Year } & \multicolumn{5}{|c|}{ Carbon emission/absorption (tons/year) } & \multirow[t]{2}{*}{ TE } & \multirow[t]{2}{*}{ TA } & \multirow[t]{2}{*}{ NE } \\
\hline & $A L$ & $\mathrm{BU}$ & VL & VG & WB & & & \\
\hline \multirow[t]{2}{*}{2000} & 9430.6 & 63,405 & -1.106 & $-29,506$ & -3860 & 72,835 & 33,365 & 39,470 \\
\hline & $12.95 \%$ & $87.05 \%$ & $0.00 \%$ & $88.45 \%$ & $11.56 \%$ & $100.00 \%$ & $100.00 \%$ & \\
\hline \multirow[t]{2}{*}{2010} & 12,288 & 81,460 & -11.35 & $-11,587$ & -2867 & 93,747 & 14,466 & 79,281 \\
\hline & $13.11 \%$ & $86.89 \%$ & $0.08 \%$ & $80.08 \%$ & $19.82 \%$ & $100.00 \%$ & $100.00 \%$ & \\
\hline \multirow[t]{2}{*}{2020} & 3217.9 & 94,885 & -0.363 & $-11,746$ & -3741 & 98,103 & 15,488 & 82,615 \\
\hline & $3.28 \%$ & $96.72 \%$ & $0.00 \%$ & $75.83 \%$ & $24.15 \%$ & $100.00 \%$ & $100.00 \%$ & \\
\hline
\end{tabular}

$\mathrm{TE}=$ Total Carbon emissions, $\mathrm{TA}=$ Total carbon absorptions, $\mathrm{NE}=$ Net carbon emissions 

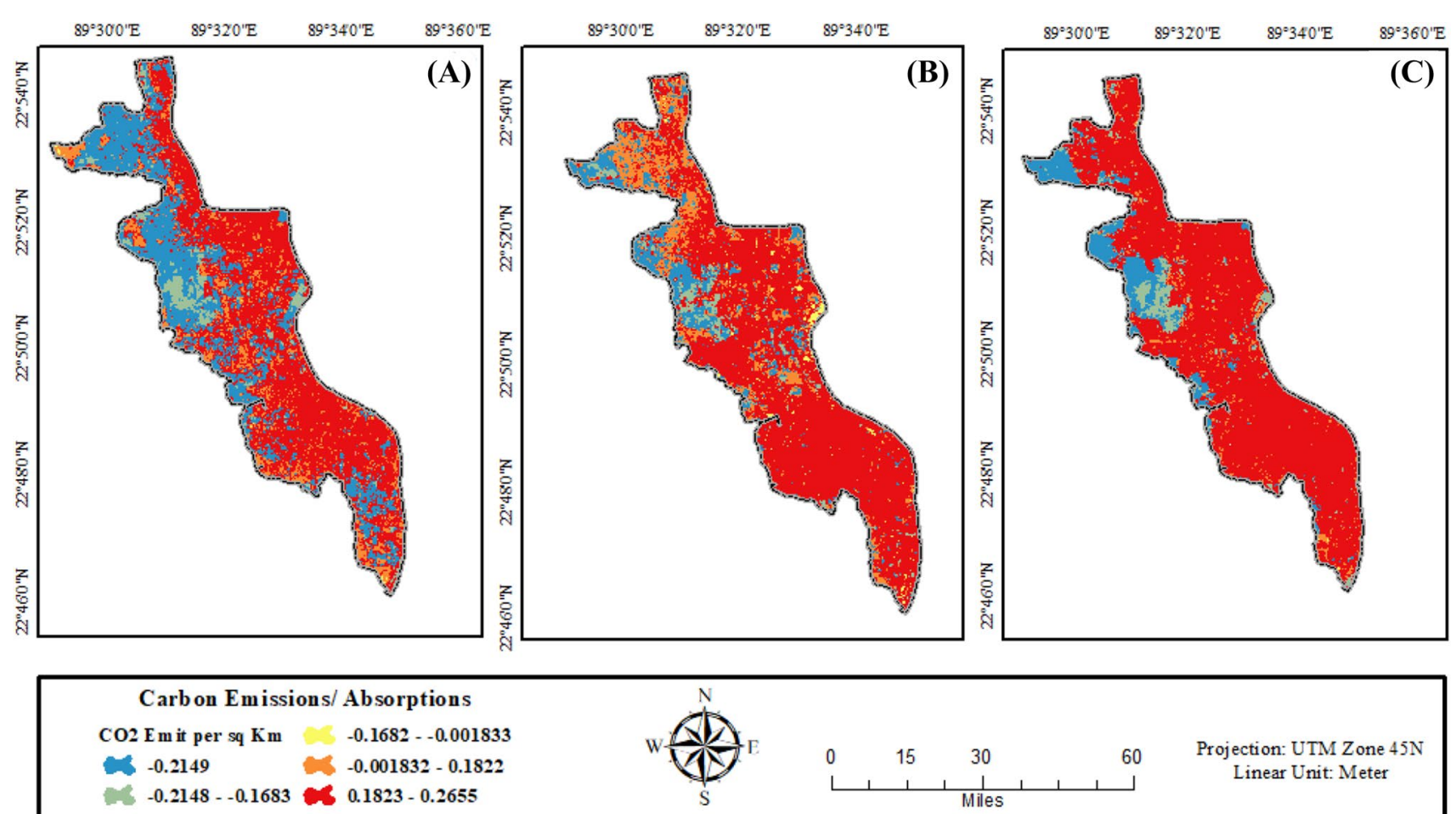

Projection: UTM Zone $45 \mathrm{~N}$

Linear Unit: Meter

Fig. 7 Carbon emission and absorption map of KCC in a 2000 b 2010 and c 2020

agricultural land. Due to the transformation of this LULC type, this amount decreased to 3217.9 tons in the year 2020. Over the last two decades, the total amount of CEs increased by 25,267 tons and absorptions decreased by 17,877 tons. Net carbon emission increased from 39,470 to 82,615 tons, which is more than double with an average growth rate of 2157.3 tons/year. The total amount of carbon absorption also reduced by a rate of 893.85 tons/year during 2000-2020 and now it is half of the year 2000. The spatiotemporal CEs pattern shows that the intensity of CEs is increasing mostly in the southwest portion of the city. Due to the growth center of Khulna city being in this portion, the urbanization trend was observed relatively high so as CEs intensity.

\subsection{LST change analysis}

Spatiotemporal LST distribution was extracted from Landsat Thermal bands for all the study year. The LST value was divided into five ranges (with $4^{\circ} \mathrm{C}$ interval) $\left(19^{\circ} \mathrm{C}-25{ }^{\circ} \mathrm{C}, 25-29{ }^{\circ} \mathrm{C}, 29^{\circ} \mathrm{C}-33^{\circ} \mathrm{C}, 33^{\circ} \mathrm{C}-37^{\circ} \mathrm{C}\right.$ and $\geq 37^{\circ} \mathrm{C}$ ) based on the extracted lower and higher LST values in different years (Fig. 8) and calculated the percentage of areas within each range (Table 8).

Table 8 shows that about $32.33 \%\left(14.60 \mathrm{Km}^{2}\right)$ and $67.47 \%\left(30.46 \mathrm{Km}^{2}\right)$ area was in the range of $\leq 25^{\circ} \mathrm{C}$ and between $25^{\circ} \mathrm{C}$ and $29^{\circ} \mathrm{C}$ in 2000 , while only $15.04 \%$ $\left(6.79 \mathrm{Km}^{2}\right)$ land cover was found in between $25^{\circ} \mathrm{C}$ and $29^{\circ} \mathrm{C}$ in 2010. In 2020, this percentage reduced to $0 \%$. During 2010, the LST of most of the areas (77.20\%) was in the range of $29^{\circ} \mathrm{C}-33^{\circ} \mathrm{C}$. During 2000 , the entire $\mathrm{KCC}$ area had the LST below $30^{\circ} \mathrm{C}$ while in 2020 , the minimum LST was $28.76^{\circ} \mathrm{C}$ with most of the area (53.70\%) having LSTs in the range of $33^{\circ} \mathrm{C}-37^{\circ} \mathrm{C}$ and LST of $46.08 \%$ of total areas was in the range of $29^{\circ} \mathrm{C}-33^{\circ} \mathrm{C}$. Rapid LULC transformation leads to increase buildup areas that increase impermeable layers which trigger LST and climate change.

\subsection{LST Dynamics in response to LULC and carbon emission}

\subsubsection{Association between LULC types and LST}

The average, minimum and maximum LST on different LULC types were extracted and presented in Table 9. The highest maximum LST $28.30^{\circ} \mathrm{C}, 35.82{ }^{\circ} \mathrm{C}$ and $39.20^{\circ} \mathrm{C}$ in the year 2000, 2010 and 2020, respectively, were observed in buildup areas, and second-highest LST in agricultural land by $26.25^{\circ} \mathrm{C}$ in $2000,27.52^{\circ} \mathrm{C}$ in 2010 and $36.27{ }^{\circ} \mathrm{C}$ in 2020 . The lowest LST $21.06{ }^{\circ} \mathrm{C}$ was observed in waterbodies in 2000 . The pattern of LST was changed much during 2000-2010. In 2010, the lowest 


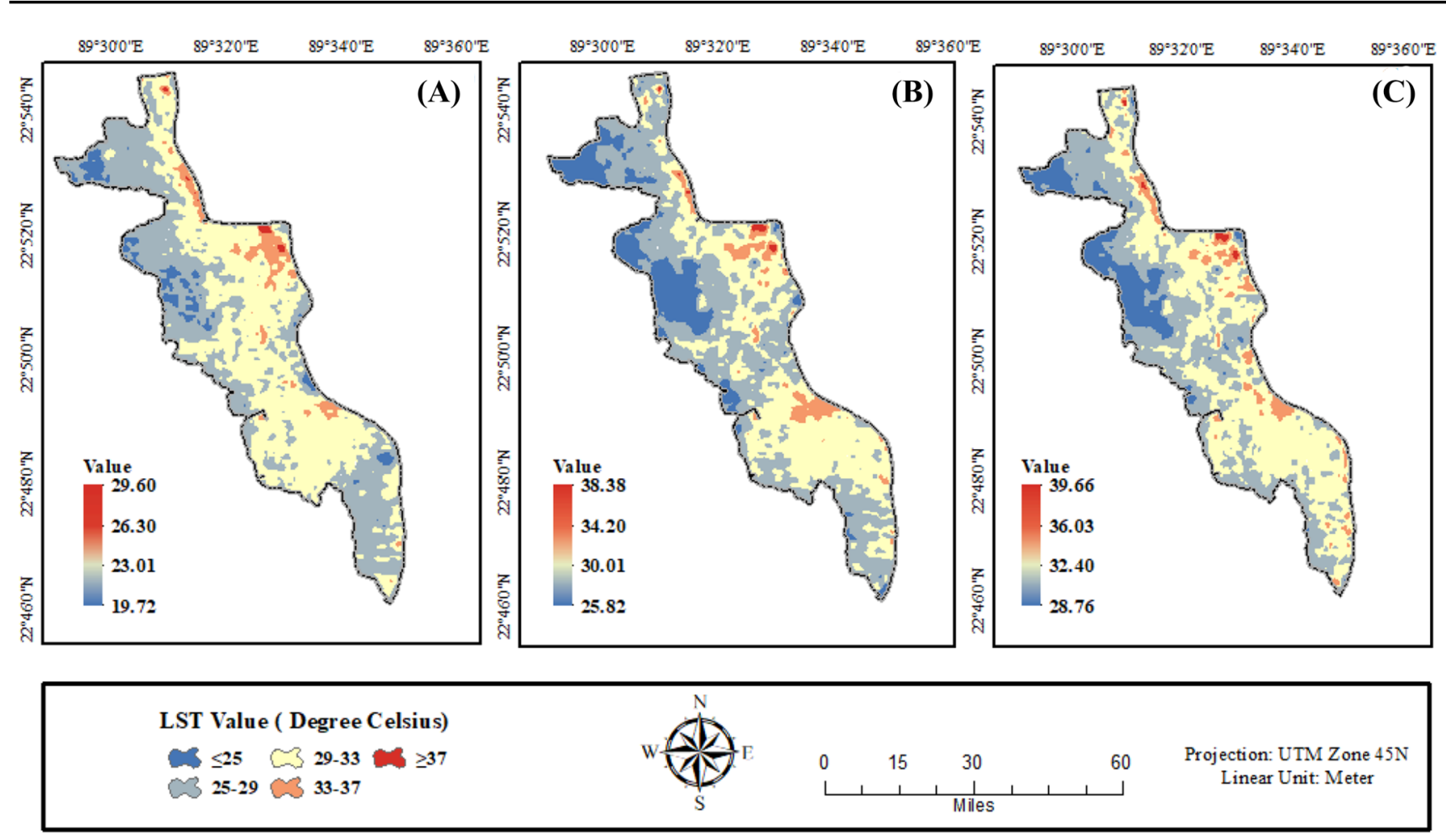

Fig. 8 Extracted spatiotemporal LST variation in the study area during a 2000, b 2010 and c 2020

Table 8 Distribution of areas in classified LST ranges during 20002020

\begin{tabular}{llcc}
\hline LST range $\left({ }^{\circ} \mathrm{C}\right)$ & \multicolumn{3}{l}{ Area in percentage } \\
\cline { 2 - 4 } & $2000(\%)$ & $2010(\%)$ & $2020(\%)$ \\
\hline$\leq 25$ & 32.33 & 0.00 & 0.00 \\
$25-29$ & 67.47 & 15.04 & 0.00 \\
$29-33$ & 0.20 & 77.20 & 46.08 \\
$33-37$ & 0.00 & 7.74 & 53.70 \\
$\geq 37$ & 0.00 & 0.02 & 0.22 \\
\hline
\end{tabular}

radiant surface temperature was observed $23.27^{\circ} \mathrm{C}$ in vegetation land cover then $23.43^{\circ} \mathrm{C}$ in buildup areas. The mean, minimum and maximum LST were also observed less in vegetation land cover in all the years due to less head absorption and transpiration. Figure 9 shows the increasing trend of mean LST of all LULC types in the study area during 2000-2020.

The local atmospheric conditions also influence LST change. An increase in atmospheric temperatures leads to a change in LST. The study used three land cover indices namely NDVI, NDWI and NDBI, and determined the correlation between LST and these indices to examine the influence of different LULC changes on LST change.
Table 9 Normalized LST in different land cover types in different years (Unit: ${ }^{\circ} \mathrm{C}$ )

\begin{tabular}{lllllll}
\hline Year & LST & AL & BU & VL & VG & WB \\
\hline 2000 & Min & 21.94 & 21.26 & 21.53 & 21.25 & 21.06 \\
& Max & 26.25 & 28.30 & 23.97 & 24.55 & 24.43 \\
2010 & Mean & 23.83 & 23.13 & 22.75 & 22.72 & 22.75 \\
& Min & 27.52 & 23.43 & 31.10 & 23.27 & 26.27 \\
& Max & 33.66 & 35.82 & 33.34 & 30.70 & 32.62 \\
& Mean & 30.30 & 28.92 & 32.22 & 28.10 & 28.62 \\
& Min & 29.69 & 23.27 & 33.54 & 23.24 & 28.26 \\
& Max & 36.27 & 39.20 & 36.02 & 33.84 & 34.34 \\
& Mean & 32.82 & 31.47 & 34.78 & 31.03 & 31.43 \\
\hline
\end{tabular}




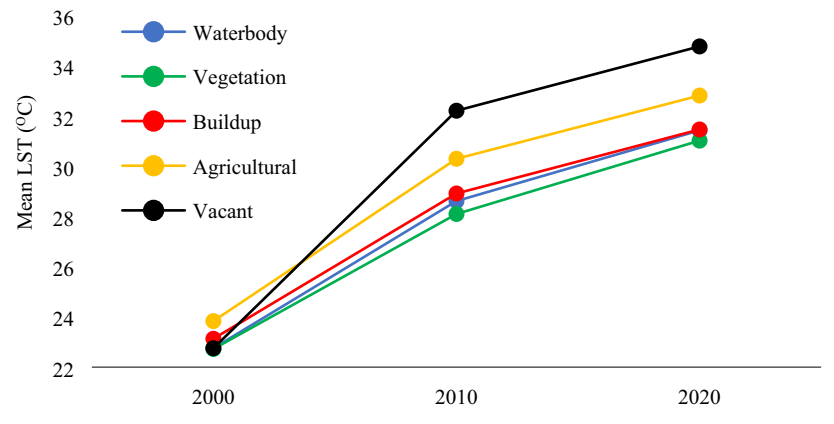

Fig. 9 Relationship between mean LSTs and the five LULC types and its change over time

Figure $10(\mathrm{~A}-\mathrm{F})$ shows the negative correlation between LST and NDVI, LST and NDWI which implies that the declination of waterbody and vegetation influenced the increase in LST in the study area. Figure 10(G-I) shows the positive correlation between LST and NDBI which indicates that the increase in buildup area increased the LST during the study period. The study found the lower value of NDVI and NDWI with the higher value of LST. Both NDVI and NDWI values were decreased during the study period that is the density of vegetation, the presence of moisture in the soil, waterbody areas were decreased. On the other hand, the NDBI value increased gradually and led to higher LST values. The higher correlation-coefficient value of the regression analysis between LST and NDVI (0.9583, $0.9693,0.9494)$, NDWI $(0.9515,0.919,0.9658)$ and NDBI $(0.979,0.9828,0.9366)$ indicates that there is a strong significant influence of LULC change in the change of LST. The relation between LST and two indices (NDVI, NDWI) indicates that the higher the vegetation and waterbody density, the lower the surface temperature. Dense forests that mean higher NDVI areas cause high evapotranspiration. The relatively high $\mathrm{R}^{2}$ values between LST and NDBI (Fig. 10) than other indices prove that increase in the buildup area has more effect on the LST growth of KCC.

\subsubsection{Association between carbon emissions and LST}

GHG emissions influence global warming. Surface temperature increases with the increase in carbon emissions [43]. This study assessed the impacts of carbon emissions on the LST change. In this communication, we have examined the correlations between CEs and LST in the GIS environment (Fig. 11). Surface temperatures showed an increasing trend with the increase in carbon emission. The lowest LST observed $19.724^{\circ} \mathrm{C}$ in carbon sinks and $27.6^{\circ} \mathrm{C}$ at the place with the CEs value $5.2 \times 10^{4}$ tons/ year. The correlation value was found highest (0.9979) for the year 2010. The mean, minimum and maximum LST (Fig. 8, 9) and the net CEs also increased mostly (Table 7) during 2000-2010. The correlation coefficient values $0.9628,0.9979$ and 0.9752 for the year 2000, 2010 and 2020 indicate the strong positive correlation between CEs and LST.

The relationship between CEs and LST implies that the increasing trend of CEs in the study area is influenced to increase LST. The increase in urban population led to the increase in urban activities which accelerated LULC transformation and carbon emissions. The reduction of carbon sink areas on large scale has reduced the capacity of carbon absorptions in Khulna and increased LST.

\subsection{Simulation of future scenario}

\subsubsection{Simulation of LULC for the year 2030 and 2040}

The MLP-MC model is used to predict the future potential LULC pattern for 2030 and 2040 (Fig. 13) by using the LULC pattern of 2000-2020. The MLP-MC is a twofold process that produces potential transition maps to buildup areas for different LULC groups. Firstly, the MLP-MC model was used for simulating LULC trends in 2020 using the LULC maps of the years 2000 and 2010 to obtain a reliable and acceptable prediction result. Table 10 shows that, with a large number of iterations, all the potential LULC types showed an overall accuracy of $94 \%$ and maximum spatiotemporal match with predicted and observed LULC classes (Fig. 12), with an $\mathrm{R}^{2}$ value of more than 0.85 and all the land cover types with more than $97 \%$ except vacant land cover (73.72\%).

The predicted LULC maps for the year 2030 in Fig. 13(A) and 2040 in Fig. 13(B) showed the significant increase in buildup areas and the reduction of other land covers (Table 11). The CA Markov LULC transformation matrix for 2020-2040 is presented in Table 12. By 2030, the buildup land cover area will increase to $35.91 \mathrm{Km}^{2}(79.55 \%)$ and by 2040, it will increase to 39.42 sq.km (87.33\%). Compared to $2020,23.38 \%$ of waterbodies and $68.48 \%$ of vegetative areas will likely be transformed to buildup areas by 2040 . Agricultural land, vacant land, waterbody and vegetation lands will cover $3.72 \%, 1.37 \%, 3.81 \%$ and $3.77 \%$ of the total KCC area, respectively, by 2040 in KCC (Table 11). Between the year 2030 and 2040, the vegetation land cover will decrease from $11.95 \%$ to $3.81 \%$. The predicted land cover area demonstrated the difference between the land cover area between the year 2000 and 2040 are, agricultural land $-3.597 \mathrm{Km}^{2}$ (7.75\% decrease), buildup area $+15.54 \mathrm{Km}^{2}$ (34.42\% increase), vacant land $+0.56 \mathrm{Km}^{2}$ ( $1.24 \%$ increase), vegetation $-12.01 \mathrm{Km}^{2}$ ( $26.61 \%$ decrease) and waterbodies $-0.589 \mathrm{Km}^{2}$ (1.30\% decrease). 

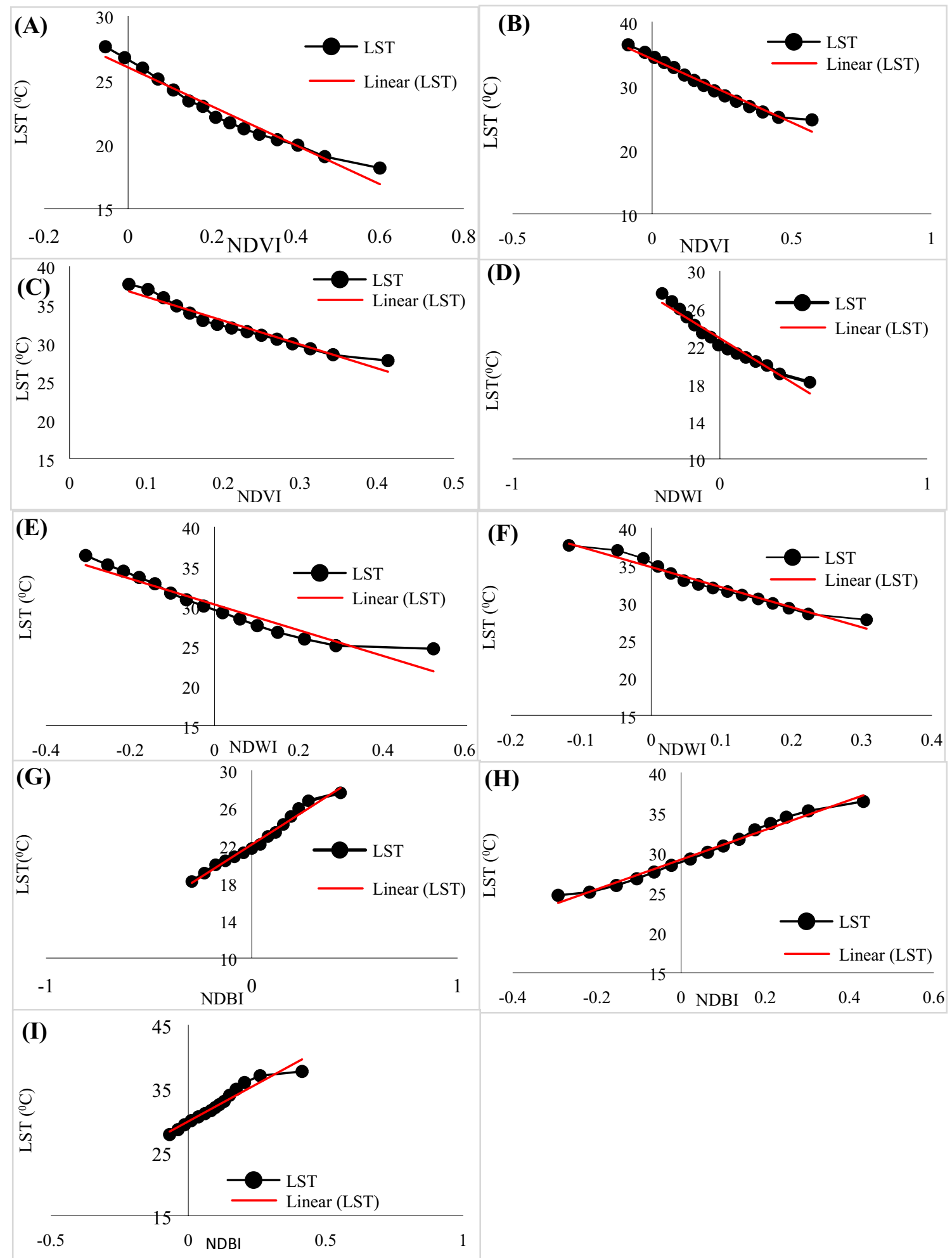

Fig. 10 Correlation between LST and NDVI a, b, c LST and NDWI d, e, f, LST and NDBI g, $\mathbf{h}, \mathbf{i}$ for the year 2000, 2010, 2020

An increase in urban population, infrastructural and economic development will lead to this rapid LULC transformation in the study regions. Potential LULC changes could adversely affect the ecosystems, environment and human health. The expansions of urban areas drive the additional LULC to CEs, higher LTS zones. If that continues, 


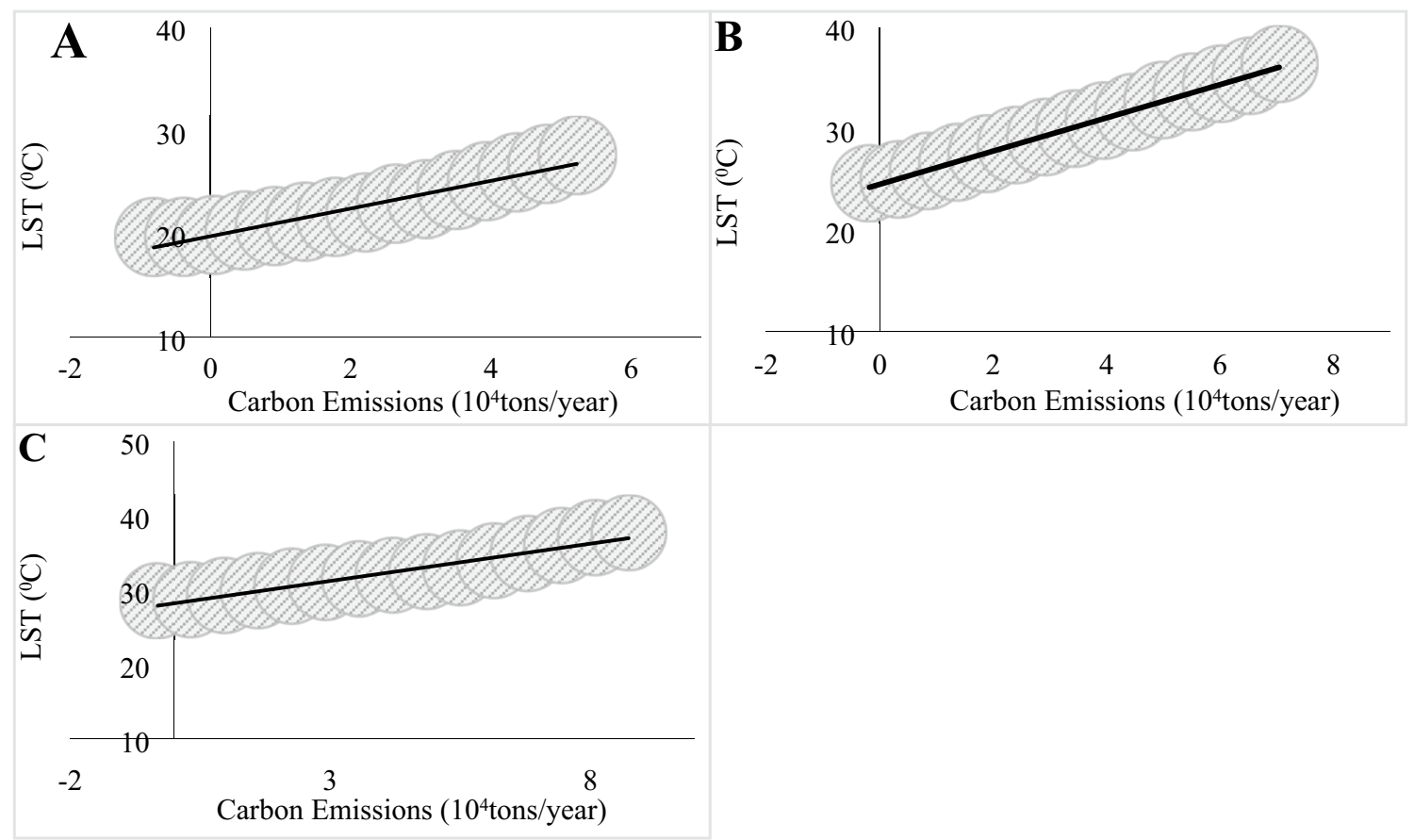

Fig. 11 Correlation between LST and CEs in the year a 2000, b 2010 and c 2020 in the study area

Table 10 Validation of predicted LULC image for the year 2020

\begin{tabular}{lcccccc}
\hline LULC types & \multicolumn{2}{l}{ Area $\left(\mathrm{Km}^{2}\right)$} & Difference & $\mathrm{R}^{2}$ & RMSE & Accuracy (\%) \\
\cline { 2 - 4 } & Actual & Predicted & & & & \\
\hline $\mathrm{AL}$ & 1.764 & 6.58 & 4.811 & 0.88 & 3.41 & 97.27 \\
$\mathrm{BU}$ & 35.694 & 31.04 & -4.650 & 0.85 & 3.29 & 99.86 \\
VL & 0.0198 & 0.54 & 0.52 & 0.90 & 0.37 & 73.72 \\
VG & 5.4567 & 5.31 & -0.143 & 0.94 & 0.10 & 99.97 \\
WB & 2.2212 & 1.64 & -0.582 & 0.89 & 0.41 & 99.73 \\
Overall accuracy & & & & & & 94.12 \\
\hline
\end{tabular}

within the next few years, KCC will face significant environmental degradation. Proper land-use planning, urban green areas and natural resource management will help to make KCC a sustainable town in the future.

\subsubsection{Simulation of carbon emissions pattern for 2030 2040}

During 2000-2020, net CEs had increased at a significant level, which is shown in Fig. 7, Table 7. Therefore, it is essential to simulate future carbon emissions and absorptions (CEA) pattern. The CEA pattern during 2000-2020 is used in the MLP-MC model to predict the future potential spatiotemporal CEA patterns for the year 2030 and 2040 which are illustrated in Fig. 14. The MLP-MC model was used for simulating the CEA pattern in 2020 using the CEA change during 2000-2010 to obtain a reliable and acceptable prediction result. The predicted 2020 CEA data were compared with the actual data for validation (Table 13). The $98.48 \%$ accuracy of the predicted data indicates the good accuracy of the CEA prediction model. The RMSE value is relatively less and the $R^{2}$ values indicate the good fit of the model [36].

The modeled CEA in the KCC area for 2030 and 2040 shows the increase in net carbon emissions. Table 14 shows that, within 2030 , the estimated total emissions will be $10.06 \times 10^{4}$ tons and absorptions will be $1.67 \times 10^{4}$ tons/ year. Build up area will contribute to $97.08 \%\left(9.77 \times 10^{4}\right.$ tons) and agricultural land to $2.98 \%\left(0.29 \times 10^{4}\right.$ tons) of total CEs in the year 2030. The CEs from the buildup area will increase to $10.73 \times 10^{4}$ tons and from agricultural land, it will increase to $0.32 \times 10^{4}$ tons by 2040 . By 2040, LULC will lose its absorption capacity and the total absorptions will be reduced to 8100 tons/year which is $23.55 \times 10^{4}$ tons less than the amount of carbon absorbed by the different LULC types in 2020. An enormous increase in the buildup 

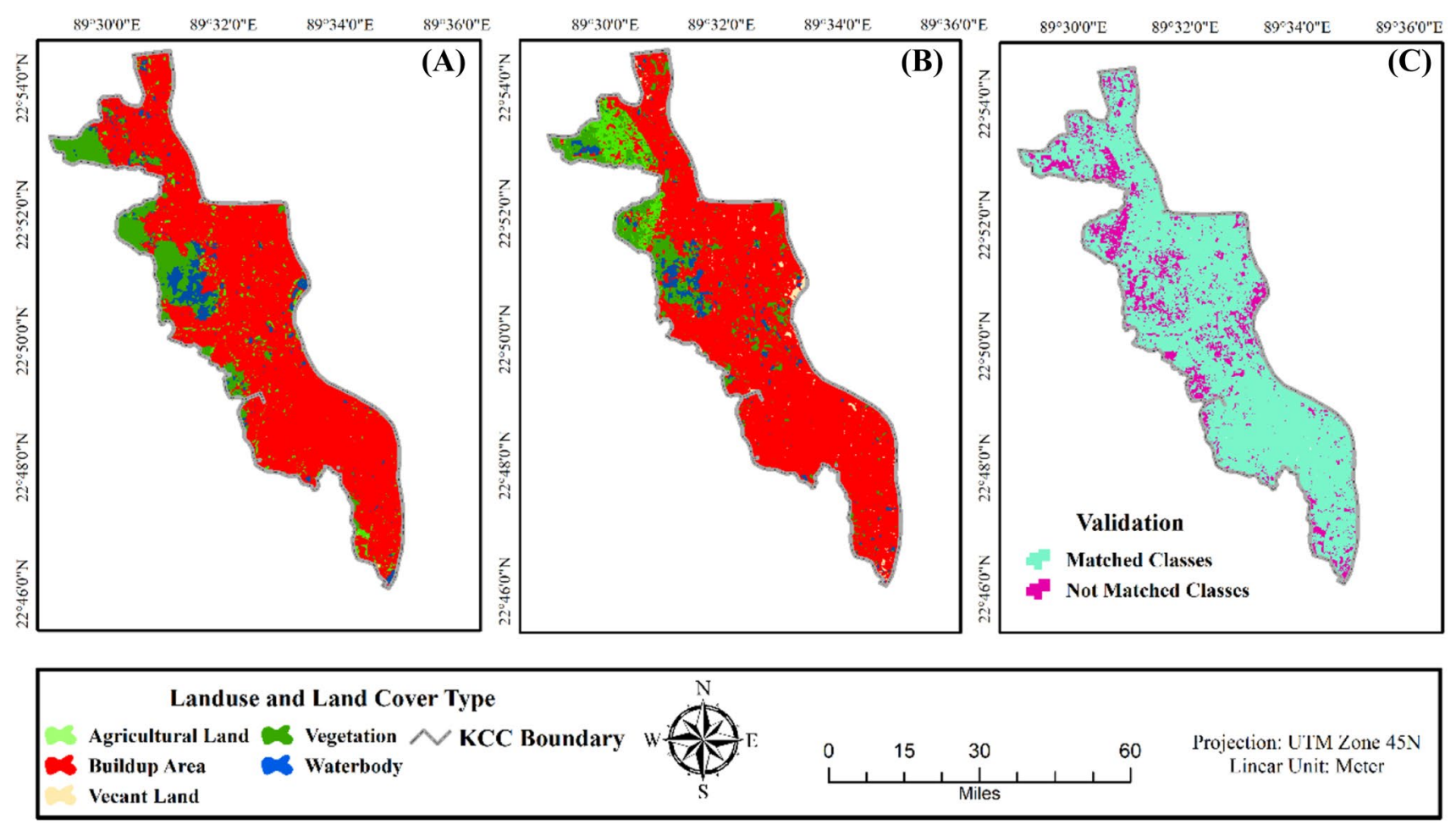

Fig. 12 Comparison of predicted and observed LULC map of 2020 a Observed b Predicted c Validated LULC map

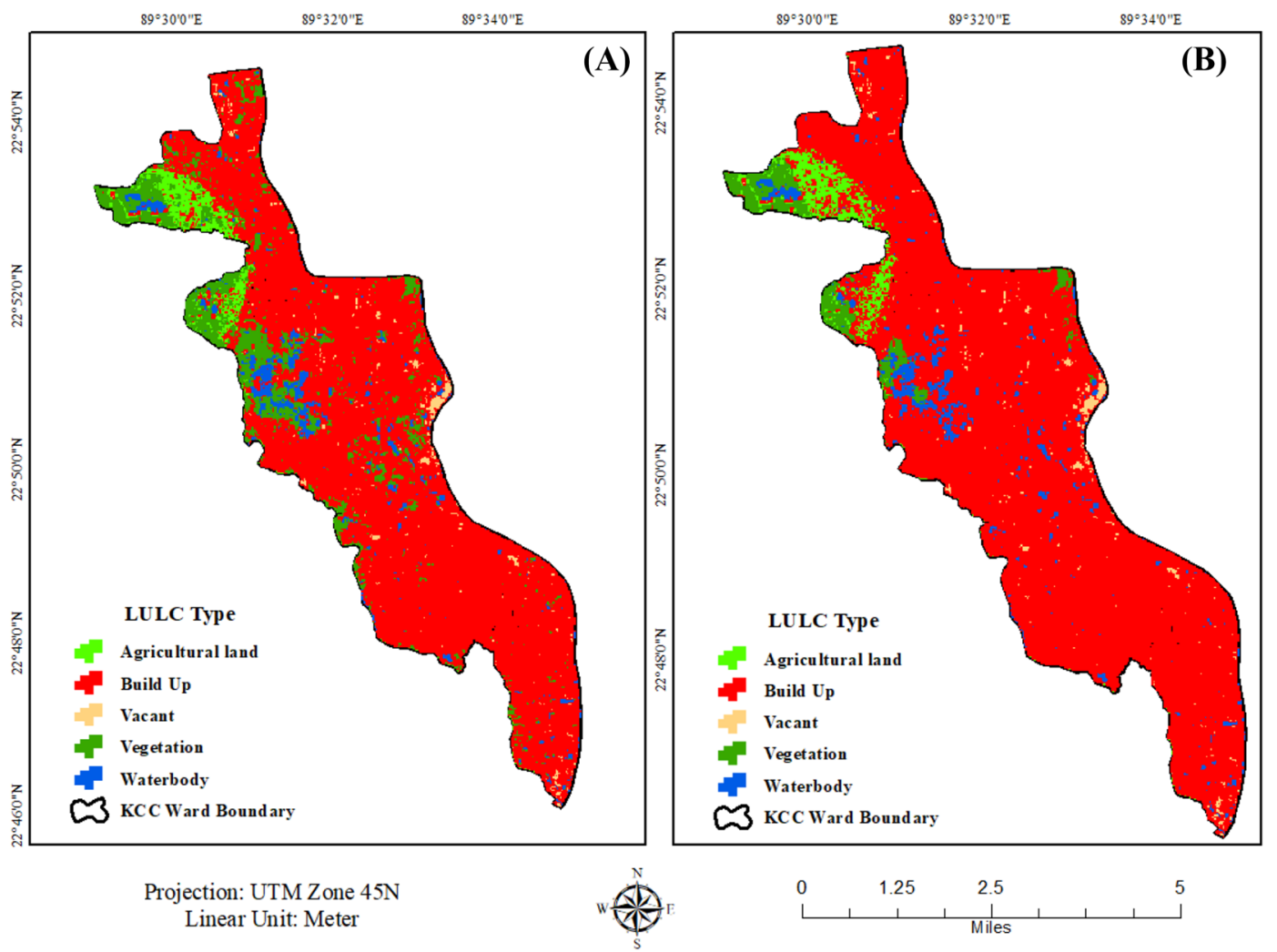

Fig. 13 Simulated LULC maps for the year a 2030 and b 2040 in the study area 
Table 11 Predicted land cover matrix for the year 2030 and 2040

\begin{tabular}{|c|c|c|c|c|c|c|}
\hline & \multicolumn{2}{|l|}{2030} & \multicolumn{2}{|l|}{2040} & \multicolumn{2}{|c|}{ Net LULC change (\%) } \\
\hline & Area & Percentage (\%) & Area & Percentage (\%) & 2020 to 2030 & 2020-2040 \\
\hline AL & 1.52 & 3.36 & 1.68 & 3.72 & -0.247 & -0.088 \\
\hline $\mathrm{BU}$ & 35.91 & 79.55 & 39.42 & 87.33 & +0.241 & +3.754 \\
\hline VL & 0.62 & 1.37 & 0.62 & 1.37 & +0.599 & +0.599 \\
\hline VG & 5.39 & 11.95 & 1.72 & 3.81 & -0.074 & -3.746 \\
\hline WB & 1.70 & 3.77 & 1.70 & 3.77 & -0.519 & -0.519 \\
\hline Total & 45.14 & 100 & 45.14 & 100 & - & - \\
\hline
\end{tabular}

Table 12 Predicted CA Markov LULC transition matrix for 2020-2040 (area in sq.km)

\begin{tabular}{llllllr}
\hline For 2020-2030 & \multicolumn{7}{l}{ V } & & & \\
\hline LULC types & $\mathrm{AL}$ & $\mathrm{BU}$ & $\mathrm{VL}$ & $\mathrm{VG}$ & WB & Total \\
\hline $\mathrm{AL}$ & 0.0574 & 1.5824 & 0.1238 & 0.0680 & 0.0149 & 1.846 \\
$\mathrm{BU}$ & 0.9496 & 32.1105 & 0.3724 & 1.6801 & 0.4291 & 35.542 \\
VL & 0.0009 & 0.0133 & 0.0011 & 0.0030 & 0.0006 & 0.019 \\
VG & 0.3946 & 1.4519 & 0.0215 & 2.9902 & 0.5647 & 5.423 \\
WB & 0.0669 & 0.7972 & 0.0986 & 0.6722 & 0.6792 & 2.314 \\
Total & 1.4695 & 35.9553 & 0.6173 & 5.4133 & 1.6885 & 45.144 \\
For 2030-2040 & & & & & & \\
AL & 1.5183 & 0.00 & 0.00 & 0.00 & 0.00 & 1.5183 \\
BU & 0.1593 & 35.750 & 0.00 & 0.00 & 0.00 & 35.910 \\
VL & 0.00 & 3.672 & 0.6192 & 0.00 & 0.00 & 0.6192 \\
VG & 0.00 & 0.00 & 0.00 & 1.7208 & 0.00 & 5.3928 \\
WB & 0.00 & 0.00 & 0.00 & 0.00 & 1.7037 & 1.7037 \\
Total & 1.6776 & 39.423 & 0.6173 & 1.7208 & 1.7037 & 45.144 \\
\hline
\end{tabular}

area will lead to maximum CEs $\left(11.05 \times 10^{4}\right.$ tons $)$ and net carbon emissions $\left(10.24 \times 10^{4}\right.$ tons) in 2040 . The amount of carbon emissions in 2040 will be $12.39 \times 10^{4}$ tons more than in 2020 and net carbon emissions will be $19.82 \times 10^{4}$ tons more.

Since the CEs simulation was performed based on the previous (2000-2020) trend, the dominations of higher CEs from buildup areas affected the simulation significantly. The greeneries or vegetative areas contribute the most to carbon absorptions [32], and this study found the massive declination of vegetative land cover in KCC in the future. This will affect the carbon absorption capacity of the study area and accelerate carbon emissions. One of the effective ways to increase carbon sequestration capacity and reduce CEs by increasing green space through plantations and preserving existing vegetative areas and waterbodies.

\subsubsection{Simulation of surface temperature for the year 2030 and 2040}

During 2000 to 2020, a remarkable increase has been observed in LST. Therefore, LST was simulated for 2030 to 2040 using the MLP-MC model which are illustrated in Fig. 15, Tables 15 and 16. Calculating $\mathrm{R}^{2}$, differences, accuracy and RMSE, the accuracy of the simulation was validated by the observed and predicted LST values for 2020 (Table 17). The $R^{2}$ values $0.87,0.82,0.88$ and the RMSE values $0.33,2.68$ and 0.88 for minimum, maximum and mean predicted LST indicate the good fit and good accuracy of the simulated LST model $[10,36]$.

The simulated LSTs for the year 2030 show that about $44.87 \%$ of the total study area will have LST from $36^{\circ} \mathrm{C}$ to $38{ }^{\circ} \mathrm{C}$ and $88.16 \%\left(39.80 \mathrm{Km}^{2}\right)$ areas LST will be more than $34^{\circ} \mathrm{C}$. In 2040 , the maximum area which is $33.18 \%$ $\left(14.977 \mathrm{Km}^{2}\right)$ will be recorded in the range of $39^{\circ} \mathrm{C}-41^{\circ} \mathrm{C}$, followed by $26.78 \%\left(12.089 \mathrm{Km}^{2}\right)$ area in the range of $41{ }^{\circ} \mathrm{C}-43^{\circ} \mathrm{C}$. The simulated LST in this study in 2040 illustrates that the majority of the KCC area (69.54\%) will have a surface temperature of more than $39^{\circ} \mathrm{C}$. The minimum LST value will be recorded as $32.11^{\circ} \mathrm{C}$ in 2030 and $34.76^{\circ} \mathrm{C}$ in 2040. The average LST will be $36.764^{\circ} \mathrm{C}$ by 2030 and $39.008^{\circ} \mathrm{C}$ by 2040 while the maximum LST will be recorded as, respectively, $44.282^{\circ} \mathrm{C}$ and $47.939^{\circ} \mathrm{C}$ in the study area. Compared to 2020 , the mean, minimum and maximum LST will increase by $4.798{ }^{\circ} \mathrm{C}, 6.004^{\circ} \mathrm{C}$ and $8.2795^{\circ} \mathrm{C}$ by 2040 (Table 16).

Simulated LST for the year 2030 and 2040 shows the variation of mean, maximum and minimum LST at a 


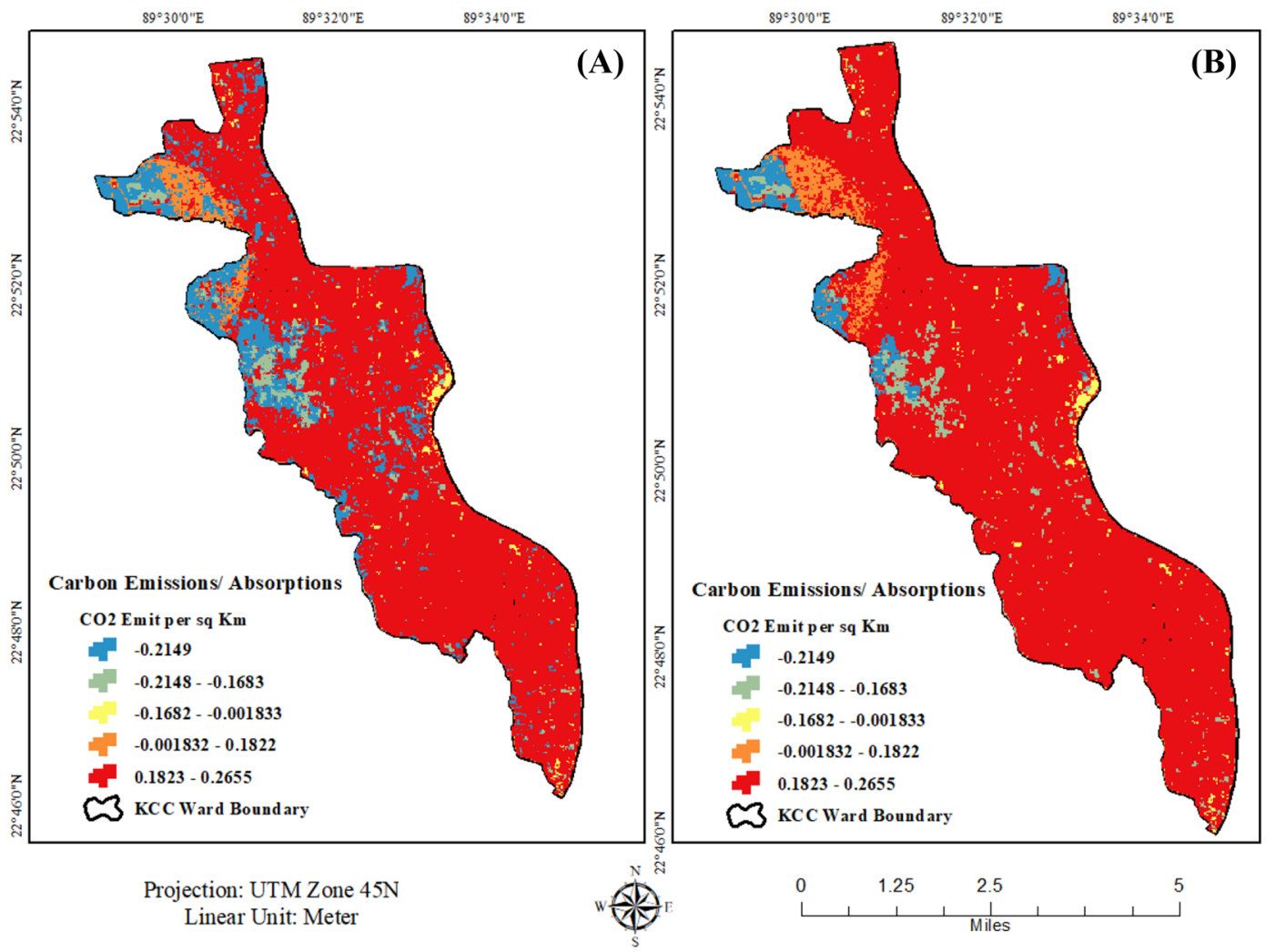

Fig. 14 Simulated Carbon Emissions maps for the year a 2030 and b 2040

Table 13 Validation of predicted CEA model for the year 2020

Table 14 Predicted Carbon Emissions and Absorptions matrix for the year 2030 and 2040

\begin{tabular}{lcccccc}
\hline LULC types & \multicolumn{2}{l}{$\begin{array}{l}\text { Carbon Emissions/Absorptions (Unit: } \times 10^{4} \\
\text { tons/year) }\end{array}$} & $\mathrm{R}^{2}$ & RMSE & Accuracy (\%) \\
\cline { 2 - 5 } & Actual & Predicted & Difference & & & \\
\hline $\mathrm{AL}$ & 0.33 & 1.21 & 0.89 & 0.88 & 3.41 & 96.59 \\
$\mathrm{BU}$ & 9.71 & 8.45 & -1.27 & 0.85 & 3.29 & 96.71 \\
VL & 0.00 & -0.10 & -0.09 & 0.90 & 0.37 & 99.63 \\
VG & -1.29 & -1.26 & 0.03 & 0.94 & 0.10 & 99.90 \\
WB & -0.37 & -0.28 & 0.10 & 0.89 & 0.41 & 99.59 \\
Overall Accuracy & & & & & & 98.48 \\
\hline
\end{tabular}

\begin{tabular}{|c|c|c|c|c|c|c|c|c|c|c|c|}
\hline \multirow[t]{2}{*}{ Year } & \multicolumn{6}{|c|}{ Predicted values (Unit: $\times 10^{4}$ tons/year) } & \multicolumn{5}{|c|}{ Difference from 2020} \\
\hline & $\mathrm{AL}$ & BU & VL & VG & WB & TE & TA & NE & TE & TA & NE \\
\hline \multirow[t]{2}{*}{2030} & 0.29 & 9.77 & -0.11 & -1.2 & -0.29 & 10.06 & -1.67 & 8.39 & +2.53 & +12.62 & +12.68 \\
\hline & $2.92 \%$ & $97.08 \%$ & $6.74 \%$ & $76.14 \%$ & $17.12 \%$ & $100 \%$ & $100 \%$ & & & & \\
\hline \multirow[t]{2}{*}{2040} & 0.32 & 10.73 & -0.11 & -0.41 & -0.29 & 11.05 & -0.81 & 10.24 & +12.39 & -23.55 & +19.82 \\
\hline & $2.93 \%$ & $97.07 \%$ & $13.99 \%$ & $50.46 \%$ & $35.55 \%$ & $100 \%$ & $100 \%$ & & & & \\
\hline
\end{tabular}

significant level in different land cover types. Table 16 shows that the mean, minimum and maximum surface temperature in the different land cover types of the study area will increase significantly. By 2040, the average LST will be recorded as $37.53{ }^{\circ} \mathrm{C}$ in agricultural land cover, $37.72{ }^{\circ} \mathrm{C}$ in buildup area, $41.03^{\circ} \mathrm{C}$ in vacant land, $37.13^{\circ} \mathrm{C}$ in vegetation and $38.43^{\circ} \mathrm{C}$ in waterbody areas.

\section{SN Applied Sciences}




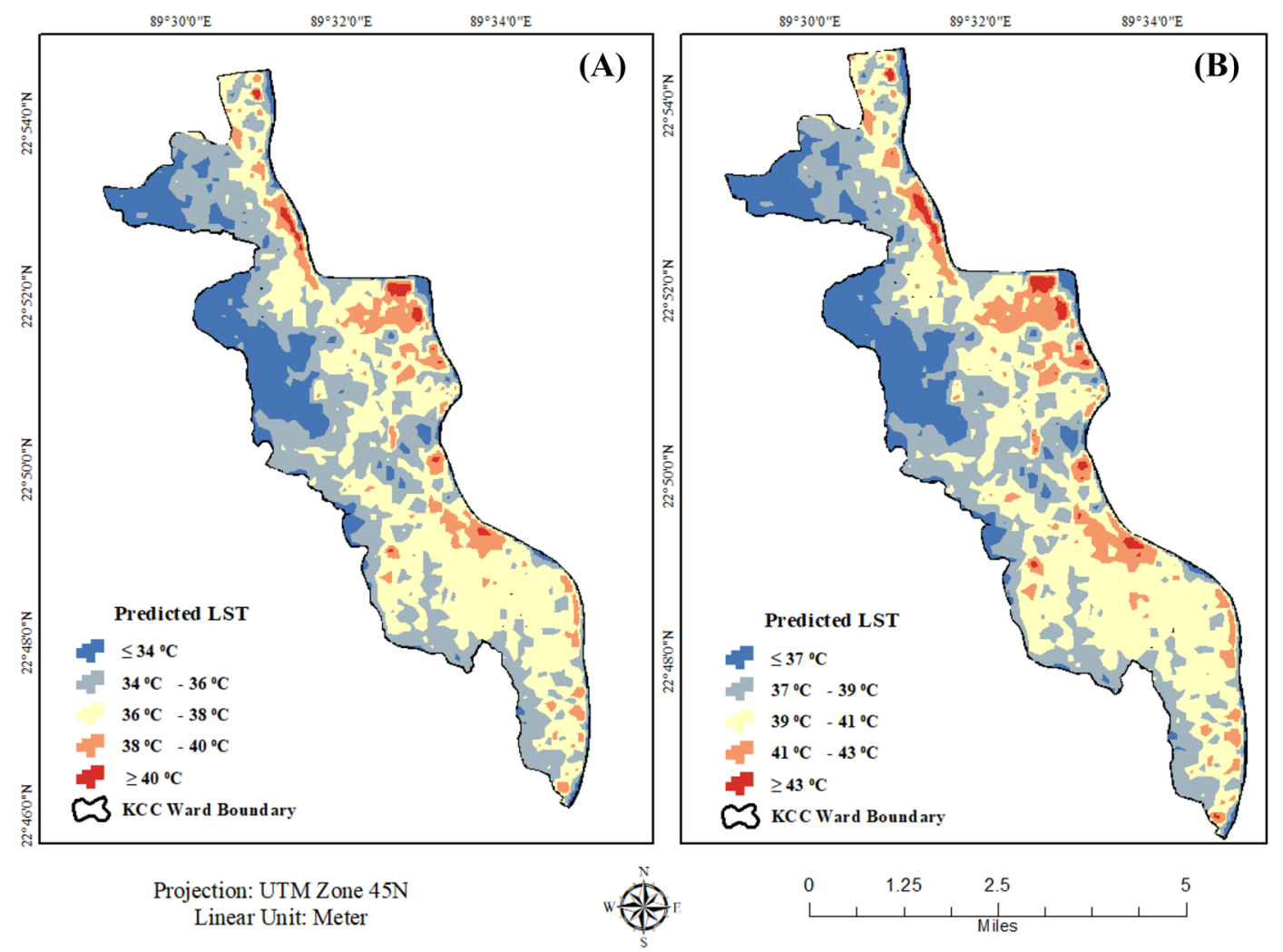

Fig. 15 Simulated LST maps for the year a 2030 and b 2040

Table 15 Validation of predicted LST model for 2020

\begin{tabular}{llllllll}
\hline LST & Actual & Predicted & Difference & Error (\%) & R2 & RMSE & Accuracy (\%) \\
\hline Minimum & 28.7602 & 29.232 & 0.4718 & 1.6405 & 0.87 & 0.33 & 99.98 \\
Maximum & 39.6598 & 43.4507 & 3.7909 & 9.5585 & 0.82 & 2.68 & 99.90 \\
Mean & 34.21 & 34.884 & 0.674 & 1.9702 & 0.88 & 0.48 & 99.98 \\
\hline
\end{tabular}

Table 16 Simulated surface temperature for the year 2030 and 2040

\begin{tabular}{|c|c|c|c|c|c|}
\hline \multicolumn{3}{|l|}{2030} & \multicolumn{3}{|l|}{2040} \\
\hline LST $\left({ }^{\circ} \mathrm{C}\right)$ & Area & Percentage & LST $\left({ }^{0} \mathrm{C}\right)$ & Area & Percentage (\%) \\
\hline$\leq 34$ & 5.35 & $11.84 \%$ & $\leq 37$ & 5.04 & 11.16 \\
\hline $34-36$ & 17.14 & $37.98 \%$ & $37-39$ & 8.71 & 19.30 \\
\hline $36-38$ & 20.25 & $44.87 \%$ & $39-41$ & 14.98 & 33.18 \\
\hline $38-40$ & 2.24 & $4.96 \%$ & $41-43$ & 12.09 & 26.78 \\
\hline$\geq 40$ & 0.16 & $0.36 \%$ & $\geq 43$ & 4.32 & 9.58 \\
\hline Total & 45.14 & $100.00 \%$ & Total & 45.14 & 100.00 \\
\hline
\end{tabular}

The simulated LST variations showed how the temperature of the KCC area will increase in the future. The increase in LST is influenced by increased CEs which pose a danger to the ecosystem and risk to human health. It will also degrade the standard of the urban environment by contributing to the depletion of the ozone layer and formulation of acid rain, which will affect the groundwater, infrastructure, crop and harms human health as well. To mitigate this CEs effect, a more sustainable and effective way is to increase urban green space or urban trees and recovery of waterbodies for ensuring ecological and environmental sustainability.

\section{Conclusion}

For the past two decades, the major cities of Bangladesh especially Khulna have undergone an enormous expansion of urban area resulting in the declination of vegetation, waterbodies and agricultural land cover areas. This study explored the use of artificial neural network (ANN) to simulate and forecast future potential LULC, CEA and LST pattern from a sequence of past three years 
Table 17 Simulated LST variation in different LULC types

\begin{tabular}{|c|c|c|c|c|c|c|}
\hline \multirow[t]{2}{*}{ LULC types } & \multirow[t]{2}{*}{ LST } & \multicolumn{2}{|c|}{ Predicted LST $\left({ }^{\circ} \mathrm{C}\right)$} & \multicolumn{3}{|c|}{ LST Change $\left({ }^{\circ} \mathrm{C}\right)$} \\
\hline & & In 2030 & In 2040 & $2020-2030$ & $2030-2040$ & $2000-2040$ \\
\hline \multirow[t]{3}{*}{$\mathrm{AL}$} & Min & 32.54 & 35.57 & 2.85 & 3.03 & 14.17 \\
\hline & Max & 38.70 & 41.89 & 2.29 & 3.19 & 18.43 \\
\hline & Mean & 34.53 & 37.53 & 1.42 & 2.99 & 14.64 \\
\hline \multirow[t]{3}{*}{ BU } & Min & 32.33 & 35.16 & 3.09 & 2.82 & 13.65 \\
\hline & Max & 35.34 & 43.47 & 3.82 & 8.13 & 16.58 \\
\hline & Mean & 34.09 & 37.72 & 2.96 & 3.62 & 14.01 \\
\hline \multirow[t]{3}{*}{ VL } & Min & 33.37 & 36.47 & 1.88 & 3.08 & 14.42 \\
\hline & $\operatorname{Max}$ & 38.72 & 44.43 & 3.06 & 5.71 & 18.82 \\
\hline & Mean & 37.28 & 41.03 & 4.54 & 3.75 & 17.46 \\
\hline \multirow[t]{3}{*}{ VG } & Min & 32.46 & 35.17 & 3.6 & 2.68 & 13.75 \\
\hline & Max & 35.02 & 42.10 & 5.23 & 7.08 & 19.39 \\
\hline & Mean & 34.28 & 37.73 & 4.81 & 3.44 & 15.58 \\
\hline \multirow[t]{3}{*}{ WB } & Min & 32.33 & 35.11 & 3.57 & 2.78 & 13.61 \\
\hline & Max & 35.76 & 43.71 & 3.56 & 7.95 & 17.88 \\
\hline & Mean & 34.25 & 38.43 & 3.62 & 4.18 & 16.04 \\
\hline
\end{tabular}

values at an epoch interval of 10 years within a period of 20 years (2000-2020). GIS-based Landsat image classification process shows that $26.10 \%\left(11.79 \mathrm{Km}^{2}\right)$ of other LULC types were transformed into buildup areas during 2000 to 2020 due to the effect of urbanization. This accelerated to increase CEs by 25,268 , reduce carbon absorptions by 17,887 tons and also increased LST range from $19.72{ }^{\circ} \mathrm{C}-29.60^{\circ} \mathrm{C}$ to $28.76^{\circ} \mathrm{C}-39.66^{\circ} \mathrm{C}$ during 2000-2020. The regression coefficient values more than 0.93 indicate the strong significant influence of CEs on LST change in the study area.

The simulation model stated the increase in buildup areas to $87.33 \%$ by 2040 , followed by $3.81 \%$ vegetation, $3.77 \%$ waterbodies and $3.72 \%$ agricultural land. This will lead to increase net CEs of $19.82 \times 10^{4}$ tons/year and reduced carbon absorptions capacity by $23.55 \times 10^{4}$ tons/ year by the year 2040 . The simulated LST represents that the LST range will be observed from $35.11^{\circ} \mathrm{C}$ to $44.43^{\circ} \mathrm{C}$ and in 2040 , about $59.96 \%(27.07 \mathrm{Km} 2)$ area will likely experience the LST range of $39^{\circ} \mathrm{C}$ to $43^{\circ} \mathrm{C}$. The mean, minimum and maximum LST will increase by $4.798^{\circ} \mathrm{C}, 6.0041^{\circ} \mathrm{C}$ and $8.2795^{\circ} \mathrm{C}$, respectively, by the year 2040 . This phenomenon is a clear indication of environmental unsustainability in the future due to unplanned LULC transformation in buildup areas by destroying vegetation areas and waterbodies. To slowdown this environmental degradation, the attachment of the concept of decentralization, urban greeneries and conservation of natural resources in future eco-friendly urban development plans and its proper implementation can be the potential solutions. The inclusion of this study's output will be helpful to the policymakers and responsible authorities to make Khulna city environmentally sound, inclusive, and sustainable. In this study, only land specific carbon emissions were considered for estimating CEs among the various sources of CEs. Future research may focus on how to increase the carbon sequestration capacity of existing LULC types.

\section{Compliance with Ethical Standrads}

Conflict of interest On behalf of all authors, the corresponding author states that there is no conflict of interest.

Open Access This article is licensed under a Creative Commons Attribution 4.0 International License, which permits use, sharing, adaptation, distribution and reproduction in any medium or format, as long as you give appropriate credit to the original author(s) and the source, provide a link to the Creative Commons licence, and indicate if changes were made. The images or other third party material in this article are included in the article's Creative Commons licence, unless indicated otherwise in a credit line to the material. If material is not included in the article's Creative Commons licence and your intended use is not permitted by statutory regulation or exceeds the permitted use, you will need to obtain permission directly from the copyright holder. To view a copy of this licence, visit http://creativecommons .org/licenses/by/4.0/.

\section{References}

1. Fang J, Zhu J, Wang S, Yue C, Shen H (2011) Global warming, human-induced carbon emissions, and their uncertainties. Sci China Earth Sci 54:1458

2. Al-sharif AAA, Pradhan B (2014) Monitoring and predicting land use change in Tripoli Metropolitan City using an integrated Markov chain and cellular automata models in GIS. Arab J Geosci 7:4291-4301 
3. Baccini A et al (2012) Estimated carbon dioxide emissions from tropical deforestation improved by carbon-density maps. Nat Clim Change 2:182-185

4. Cui Y, Li L, Chen L, Zhang Y, Cheng L, Zhou X, Yang X (2018) LandUse Carbon Emissions Estimation for the Yangtze River Delta Urban Agglomeration Using 1994-2016 Landsat Image Data. Remote Sens 10(6):1334

5. Duguma L et al (2019) Deforestation and Forest Degradation as an Environmental Behavior: Unpacking Realities Shaping Community Actions. Land 8(2):26

6. Stern N (2014) The Economics of Climate Change: The Stern Review. Cambridge University Press, Cambridge, United Kingdom

7. Mohajan HK (2014) Greenhouse gas emissions of China. J Environ Treat Tech 1(4):190-202

8. Basak JK, Titumir R, Dey NC (2013) Climate change in Bangladesh: A historical analysis of temperature and rainfall data. $J$ Environ 2(2):41-46

9. Jain N et al (2015) Greenhouse Gas Emission and Global Warming. In: Khoiyangbam RS, Gupta N (eds) Introduction to Environmental Sciences. TERI Press, New Delhi, pp 379-411

10. Kafy A et al (2021) Prediction of seasonal urban thermal field variance index using machine learning algorithms in Cumilla. Bangladesh Sustain Cities and Soc 64:102542

11. Islam S, Ma M (2018) Geospatial monitoring of land surface temperature effects on vegetation dynamics in the southeastern region of Bangladesh from 2001 to 2016. Int J GeoInformatrix 7(12):486

12. Quéré $C L$ et al (2009) Trends in the sources and sinks of carbon dioxide. Nat Geosci 2:831-836

13. Denman KL et al (2007) Couplings Between Changes in the Climate System and Biogeochemistry. In: Boonpragob K, Heimann M, Molina M (eds) Climate Change 2007: The Physical Science Basis. Cambridge University Press, Cambridge United Kingdom and New York NY USA, pp 501-570

14. Friedlingstein $P$ et al (2010) Update on $\mathrm{CO} 2$ emissions. Nat Geosci 3:811-812

15. Kafy A et al (2021) Remote sensing approach to simulate the land use/land cover and seasonal land surface temperature change using machine learning algorithms in a fastest-growing megacity of Bangladesh. Remote Sens Appl: Soc Environ 21:100463

16. Maduako I, Yun Z, Patrick B (2016) Simulation and Prediction of Land Surface Temperature (LST) Dynamics within Ikom City in Nigeria Using Artificial Neural Network (ANN). J Remote Sens GIS 5(1):158-165

17. Araya YH, Cabral P (2010) Analysis and Modeling of Urban Land Cover Change in Setúbal and Sesimbra. Port Remote Sens 2(6):1549-1563

18. Zheng $H$, Shen $G$, Wang $H$, Hong J (2015) Simulating land use change in urban renewal areas: A case study in Hong Kong. Habitat Int 46:3-34

19. Han H, Yang C, Song J (2015) Scenario simulation and the prediction of land use and land cover change in Beijing. China Sustain 7(4):4260-4279

20. Lin X et al (2018) Land-use/land-cover changes and their influence on the ecosystem in Chengdu City, China during the period of 1992-2018. Sustainability 10(10):3580

21. Don A, Schumacher J, Freibauer A (2010) Impact of tropical land-use change on soil organic carbon stocks-a meta-analysis. Glob Change Biol 17(4):1658-1670

22. Maheshwari $H$, Chandra U, Jain $K$ (2018) A review from greenhouse effect to carbon footprint. Pollut Res 37(4):1033-1038

23. Florides GA, Christodoulides P (2009) Global warming and carbon dioxide through sciences. Environ Int 35(2):390-401
24. Sahana M, Ahmed R, Sajjad H (2016) Analyzing land surface temperature distribution in response to land use/land cover change using split window algorithm and spectral radiance model in Sundarban Biosphere Reserve. India Model Earth Sys Environ 2(2):1-11

25. Jeevalakshmi D, Reddy D, Manikiam B (2017) Land surface temperature retrieval from LANDSAT data using emissivity estimation. Int J Appl Eng Res 12:9679-9687

26. Ning J et al (2018) Analysis of relationships between land surface temperature and land use changes in the Yellow River Delta. Frontiers Earth Sci 12:444-456

27. Peng $W$ et al (2017) Land surface temperature and its impact factors in Western Sichuan Plateau. China Geocarto Int 32(8):919-934

28. Cui $Y$ et al (2018) Land-use carbon emissions estimation for the Yangtze River Delta Urban Agglomeration using 19942016 Landsat image data. Remote Sens 10(9):1334

29. Achmad A, Zainuddin MM (2019) The relationship between land surface temperature and water index in the urban area of a tropical city. IOP Conf Series: Earth Environ Sci 365(1):012013

30. Srivastava PK, Majumdar TJ, Bhattacharya AK (2010) Study of land surface temperature and spectral emissivity using multisensor satellite data. J Earth Syst Sci 119:67-74

31. Koc A, Karahan AE, Bingul MB (2019) Determination of Relationship Between Land Surface Temperature and Different Land Use by Chaid Analysis. Appl Ecol Environ Res 17(3):6051-6067

32. Parvin NS, Abudu D (2017) Estimating Urban heat Island intensity using remote sensing techniques in Dhaka City. Int J Sci Eng Res 8(4):289-298

33. Aboelnour M, Engel BA (2018) Application of remote sensing techniques and geographic information systems to analyze land surface temperature in response to land use/land cover change in greater Cairo Region. Egypt Earth Environ Sci 10(1):5969-5998

34. Mia MB, Bhattacharya R, Woobaidullah A (2017) Correlation and monitoring of land surface temperature, urban heat island with land use-land cover of Dhaka City using satellite imageries. Int J Res Geogr (IJRG) 3(4):10-20

35. Farzana K, Rahman MM (2017) Monitoring landuse/land cover change and its subsequent effects on urban thermal environment in Chittagong Metropolitan area: a remote sensing and gis based analysis. Orient Geogr 59(1):51-68

36. Kafy A et al (2020) Modelling future land use land cover changes and their impacts on land surface temperatures in Rajshahi, Bangladesh. Remote Sens Appl: Soc Environ 18(2):100314

37. Marufuzzaman M, Khanam MM, Hasan MK (2019) Exploring the Impact of Urban Growth on Surface Waterbody Area Loss in Khulna City using GIS Techniques. J Remote Sens GIS 8(2):1-5

38. Moniruzzam M et al (2018) Impact Analysis of Urbanization on Land Use Land Cover Change for Khulna City, Bangladesh Using Temporal Landsat Imagery. Int Arch Photogramm Remote Sens Spatial Inf Sci 42(5):757-760

39. Zannat M. E.-U (2012) A study on land use policies of Khulna structure plan 2000-2020 in the light of climate change induced flood scenario by Md. Esraz-Ul-Zannat" Bangladesh University of Engineering and Technology, Dhaka.

40. Subedi P, Subedi K, Thapa B (2013) Application of a Hybrid Cellular Automaton - Markov (CA-Markov) Model in Land-Use Change Prediction: A Case Study of Saddle Creek Drainage Basin. Fla Appl Ecol Environ Sci 1(6):126-132

41. Arsanjani JJ et al (2012) Integration of logistic regression, Markov chain and cellular automata models to simulate urban expansion. Int J Appl Earth Obs Geoinform 21(1):265-275

42. Williams RG et al (2017) Sensitivity of Global Warming to Carbon Emissions: Effects of Heat and Carbon Uptake in a Suite of Earth System Models. J Clim 30(23):9343-9363 
43. Allen $\mathrm{M}$ et al (2009) Warming caused by cumulative carbon emissions towards the trillionth tonne. Nature 458:1163-1166

44. Williams R et al (2016) A framework to understand the transient climate response to emissions. Environ Res Lett 11(1):15003

45. Knutti R, Hegerl GC (2008) The equilibrium sensitivity of the Earth's temperature to radiation changes. Nat Geosci 1:735-743

46. Haque MN, Saroar M, Fattah MA, Morshed SR, Fatema N (2020) Access to basic services during the transition from MDGs to SDGs: more rhetoric than reality in a Bangladesh slum. J Human Appl Soc Sci 2(4):1-19

47. Ahmed B (2011) Modelling Spatio-temporal Urban land cover growth dynamics using remote sensing and GIS techniques: $A$ case study of Khulna City. J Bangladesh Inst Plan 4:15-32

48. Morshed $S$ et al (2020) Surface temperature dynamics in response to land cover transformation. J Civil Eng, Sci Technol 11(2):94-110

49. Mondal et al (2017) Study on Rainfall and Temperature Trend of Khulna Division in Bangladesh. DEW-DROP. 4.

50. Bishta A (2018) Assessment of the reliability of supervised classifications of Landsat-7, ASTER, and SPOT-5 multispectral data in rock unit discriminations of Jabal Daf-Wadi Fatima area. Saud Arab Arab J Geosci 11(1):755

51. Oliva F, Dalmau O, Alarcón T (2014) A Supervised Segmentation Algorithm for Crop Classification Based on Histograms Using Satellite Images. Human-Insp Comput Appl 8856:327-335

52. Pontius R Jr, Millones M (2011) Death to Kappa: birth of quantity disagreement and allocation disagreement for accuracy assessment. Int J Remote Sens 32(15):4407-4429

53. Yadav K, Congalton R (2019) Correction: Yadav. K. and Congalton. R. accuracy assessment of global food security-support analysis data (GFSAD) cropland extent maps produced at three different spatial resolutions. Remote Sens 11(6):630

54. Fang J et al (2007) Terrestrial vegetation carbon sinks in China, 1981-2000. Sci China, Ser D Earth Sci 50:1341-1350
55. Hong-xin S et al (2012) Effects of Different Land Use Patterns on Carbon Emission in Guangyuan City of Sichuan Province. Bull Soil Water Conserv 32:101-106

56. Xiaonan D et al (2008) Primary evaluation of carbon sequestration potential of wetlands in China. Acta Ecol Sin 28(2):463-469

57. Hopkinson C, Cai W, Hu X (2012) Carbon sequestration in wetland dominated coastal systems - a global sink of rapidly diminishing magnitude. Curr Opin Environ Sustainability 4(2):186-194

58. Grigoraș G, Urițescu B (2019) Land Use/Land Cover changes dynamics and their effects on Surface Heat Island in Bucharest, Romania. Int J Appl Earth Obs Geoinform 80:115-126

59. Guha $S$ et al (2018) Analytical study of land surface temperature with NDVI and NDBI using Landsat 8 OLI and TIRS data in Florence and Naples city. Italy Eur J Remote Sens 51(1):667-678

60. Mishra V, Rai P (2016) A remote sensing aided multi-layer perceptron-Markov chain analysis for land use and land cover change prediction in Patna district (Bihar). India Arab J Geosci 9:249

61. Ozturk D (2015) Urban growth simulation of Atakum (Samsun, Turkey) using cellular Automata-Markov Chain and multi-layer Perceptron-Markov Chain models. Remote Sens 7(5):5918-5950

62. Alqurashi A, Kumar L, Sinha P (2016) Urban land cover change modelling using time-series satellite images: a case study of Urban Growth in Five Cities of Saudi Arabia. Remote Sens $8(10): 838$

63. Saputra M, Lee H (2019) Prediction of Land Use and Land Cover Changes for North Sumatra, Indonesia, Using an ArtificialNeural-Network-Based Cellular Automaton. Sustainability 11(11):3024

Publisher's Note Springer Nature remains neutral with regard to jurisdictional claims in published maps and institutional affiliations. 